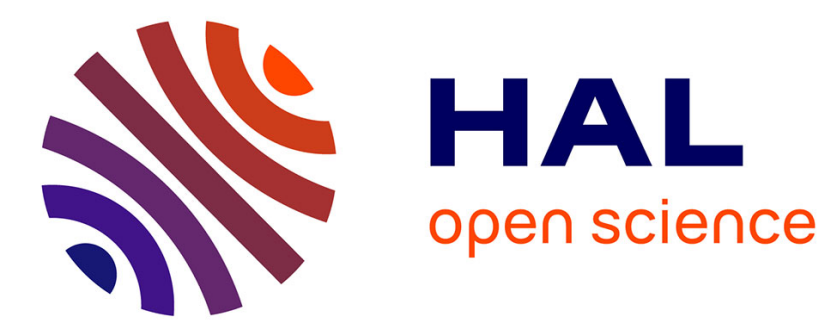

\title{
Thermodynamic evaluation of oxidation during brazing process of medium-voltage electrical circuit breakers
}

Ioana Nuta, Christian Chatillon, Francois Chombart, Amelie Moreau

\section{To cite this version:}

Ioana Nuta, Christian Chatillon, Francois Chombart, Amelie Moreau. Thermodynamic evaluation of oxidation during brazing process of medium-voltage electrical circuit breakers. Metallurgical Research \& Technology, 2016, 113 (5), pp.510. 10.1051/metal/2016031 . hal-01965221

\section{HAL Id: hal-01965221 \\ https://hal.science/hal-01965221}

Submitted on 25 Dec 2018

HAL is a multi-disciplinary open access archive for the deposit and dissemination of scientific research documents, whether they are published or not. The documents may come from teaching and research institutions in France or abroad, or from public or private research centers.
L'archive ouverte pluridisciplinaire HAL, est destinée au dépôt et à la diffusion de documents scientifiques de niveau recherche, publiés ou non, émanant des établissements d'enseignement et de recherche français ou étrangers, des laboratoires publics ou privés. 


\title{
Thermodynamic evaluation of oxidation during brazing process of medium-voltage electrical circuit breakers
}

\author{
Ioana Nuta ${ }^{1,2}$, Christian Chatillon ${ }^{1,2}$, Francois Chombart ${ }^{3}$ and Amélie \\ Moreau ${ }^{4}$ \\ 1 University Grenoble Alpes, SIMAP, 1130 rue de la piscine BP 75, 38402 Saint Martin d'Hères, France \\ e-mail: ioana.nuta@simap.grenoble-inp.fr \\ 2 CNRS, SIMAP (UMR-5266) , 38000 Grenoble, France \\ 3 Schneider Electric- SEA, ZI de Ripotier, BP 133, 07202 Aubenas Cedex, France \\ 4 Schneider Electric- ZAC St Ange 4, rue de I'Industrie, 38760 Varces Allieres et Risset, France
}

Key words:

Vacuum circuit breakers; vacuum bottle; vacuum interrupters; brazing; thermodynamics; vaporization; condensation; oxygen transport; oxygen impurity; vacuum conditions; vacuum furnace

\section{Received 11 February 2016} Accepted 13 May 2016

\begin{abstract}
The present study is a thermodynamic analysis of the different molecular flows occurring during the vacuum brazing of electrical vacuum bottles also called Vacuum Interrupters (mentioned later as $\mathrm{VI}$ ). Among the available impurities either coming from the Vacuum Interrupters components materials or from vacuum technology, the analysis is focused on the oxygen since this impurity leads to formation of the more stable compounds, i.e. oxides. During the brazing cycles the resistors of the vacuum furnace and the VI materials including some braze components are the main sources of vapours that partly escape or make deposits on colder parts of the furnace. Vaporization and condensation processes are evaluated, their matter flows quantified and finally their interaction with residual oxygen calculated through a balance between input oxygen from vacuum or neutral gas and the different sources of oxygen coming from the parts under treatment. The enrichment of the VI materials and deposits with oxygen is evaluated as well as the limits required for vacuum conditions. The main conclusion is that present vacuum conditions allow correct working of the brazing sequence but in any other temperature steps or ramps, oxygen is trapped as oxides at the surface of the parts or accumulated in the bulk materials of the furnace.
\end{abstract}

o protect an electrical circuit from a
damage caused by overload or short
circuit, circuit breakers are used. For
medium-voltage class, i.e., between 1 and
$50 \mathrm{kV}_{\mathrm{AC}}$, Vacuum Interrupters (VIs) are to-
day one of the dominant technology world-
wide installed as switchgears: the current
interruption is made by creating and extin-
guishing an electrical arc in a vacuum con-
tainer [1-3]. Vacuum (typically $\approx 10^{-4} \mathrm{~Pa}$,
for a new VI) has good dielectric prop-
erties remarkable enough to use it has a
mean to break a defect current. By remov-
ing absorbed gases and impurities from
the metallic parts before or during the de-
vice manufacturing, certain chemical com-
pounds detrimental to the arc control system
efficiency are eliminated. The VIs can oper-
ate up to $36 \mathrm{kV}$ (for medium voltage range)

and pressure level below $0.01 \mathrm{~Pa}\left(10^{-4} \mathrm{mbar}\right)$ is guaranteed 30 years.

Sometimes, despite of high quality vacuum conditions during brazing process, some coloured layers with a varied degree of adherence are observed on metals, ceramics, and on alloys parts. These coloured layers may be observed after brazing treatment on around $15 \%$ of the parts in one furnace load and microscopic studies show that these layers are oxides. The thickness of these oxide films alternately increase or decrease due to the daily brazing cycles changes in furnace temperature as there are several VI ranges to manufacture. This is mandatory to master this oxide layer deposit mainly depending on temperature because brazing cycles generate more or less desorbed oxygen flows during the next temperature ramp. To understand the origin of these oxide layers

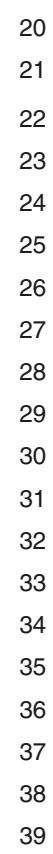

20 21 22 23 24 25 26 27 28 29 30 31 32 33 34 35 36 37 38 39 


$$
\text { “metal160019" - 2016/6/9 - 11:29 - page } 2 \text { - \#2 }
$$

I Nuta et al.: Metall. Res. Technol.

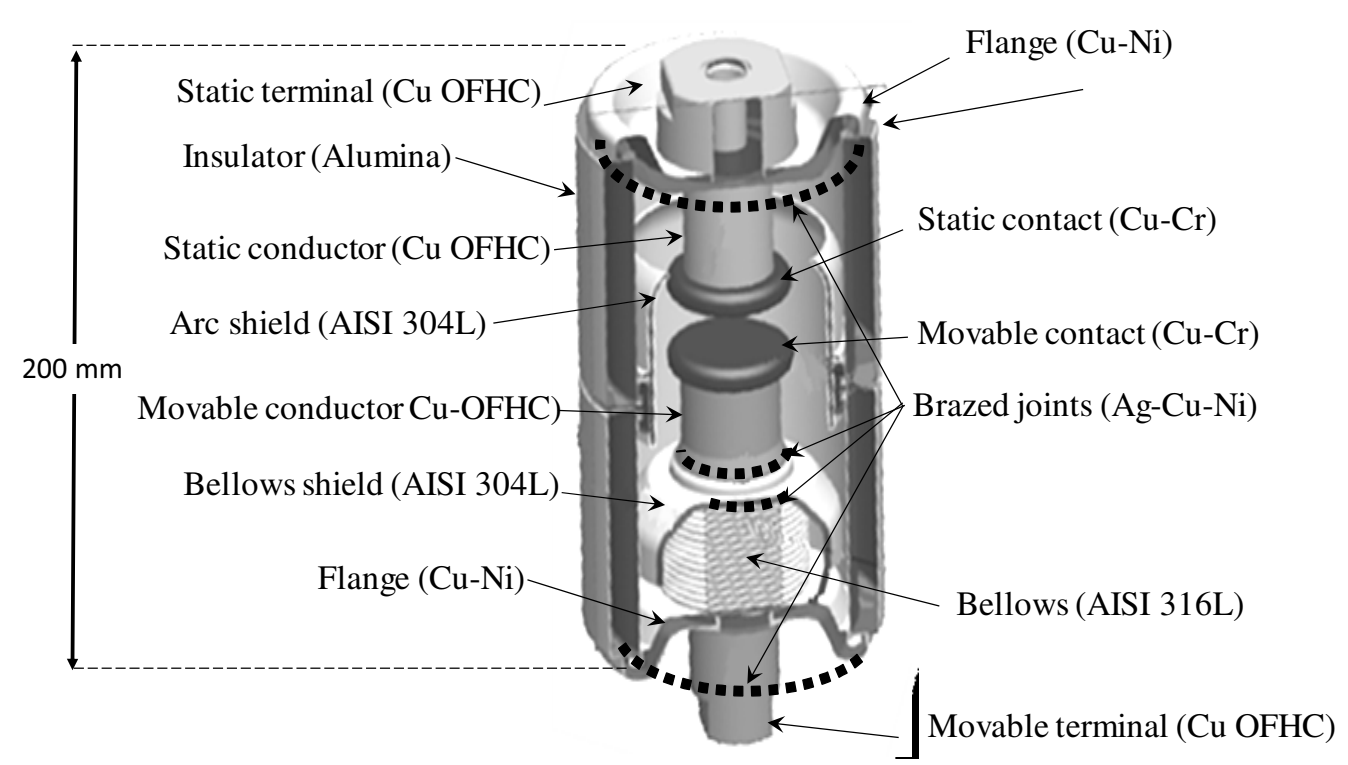

Fig. 1. Description of main parts of a Schneider vacuum circuit breaker for medium voltage.

1 and quantify their thicknesses, the purpose 2 of the present study is: (i) to identify the 3 vapour composition during brazing process 4 under vacuum; (ii) to analyse the exchanges 5 of the molecular flows between different 6 parts of the furnace/VI and thus evaluate 7 the deposits; (iii) to evaluate the influence 8 of cooling gas as well as of pumping pres9 sure limits on the oxides formation. Thermo10 dynamic calculation of the vaporization and 11 condensation of different components (i.e. 12 metallic parts and brazing material) as well 13 as of adsorption of oxygen are performed. 14 The present work on vacuum bottles seal15 ing is to determine the critical level for the 16 residual vacuum in the furnaces and to spot 17 which kind of gaseous species have a ma18 jor significance during brazing cycle on the 19 furnace specifications degradation. joints are: bellows to-rod, flange to insulator, flange to bellows, rod to contact tip, and bellows to shield.

At Schneider Electric Company brazing operations are made in a secondary vacuum type industrial furnace (ECM Technologies, Technisud, 38029 Grenoble at www.ecm-furnaces.com). A typical industrial brazing furnace is described in Figure 2 a. The central part of the furnace is the casing. It is built as practically a closed box with packed thermal shields and resistors holders. The casing is mainly pumped by the front and back apertures A VI load (about 100 VIs) brazed in an only one cycle is heated using arrays of molybdenum heating elements hold inside the casing and close to its internal side (first thermal shield). The arrays surround the whole parts and, in this manner, heat can be provided homogeneously. The heating elements, with a large surface of $5.19 \mathrm{~m}^{2}$ are made of molybdenum. The first thermal shield is made of molybdenum too and others in stainless steel. Their number guarantees a good thermal shielding and a homogeneous temperature of the load Typically, the temperature gradient between the load and the first thermal shield amount to 10 to $20 \mathrm{~K}$ degree difference, the thermal shield temperature being lower than the load temperature. 


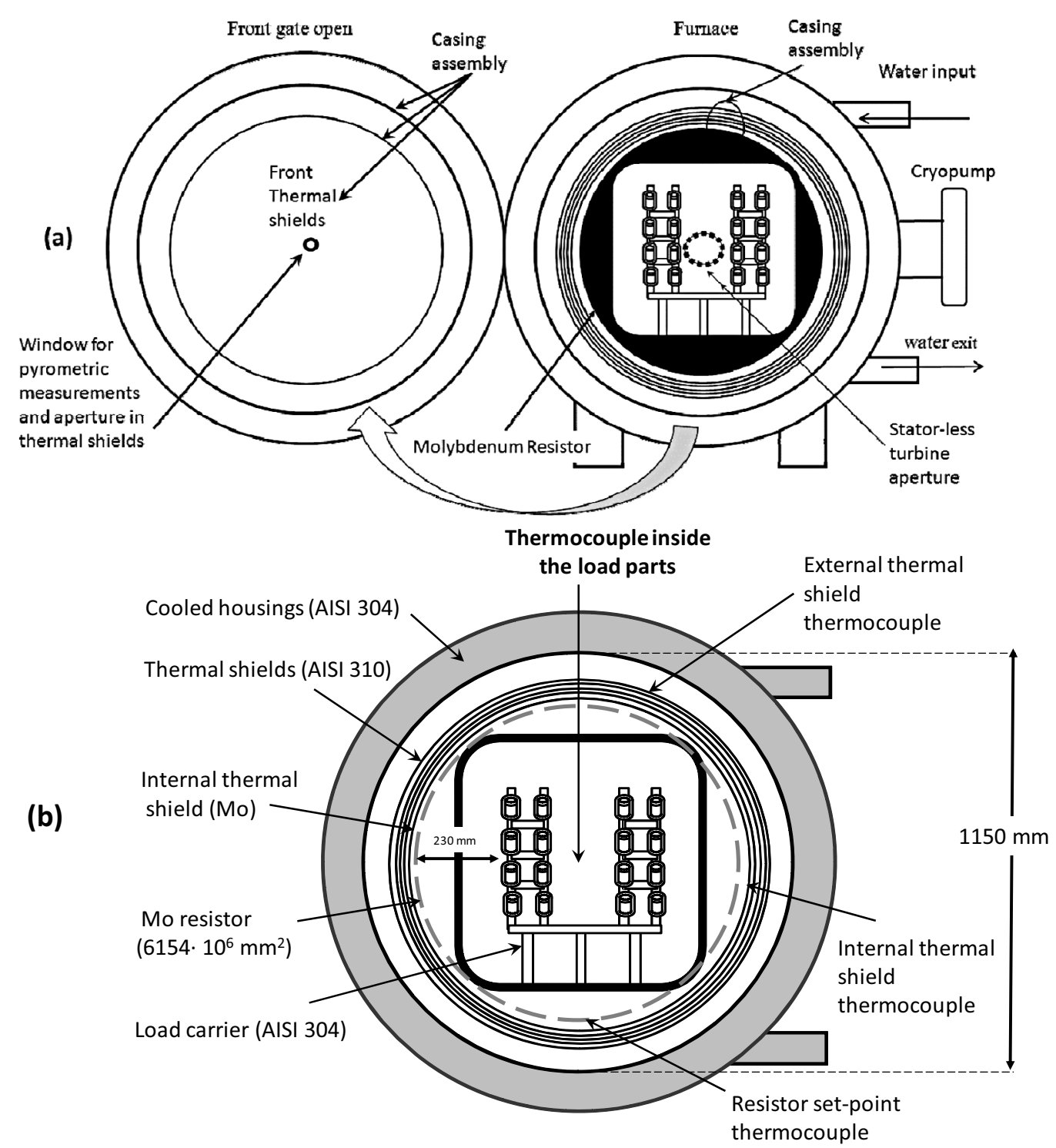

Fig. 2. Schematic description of a ECM vacuum furnace for brazing process of vacuum circuit breakers: (a) general view, (b) Details for location of different temperature measurements.

Vacuum, typically $0.0002 \mathrm{~Pa}(2 \times$ $10^{-6}$ mbar) at room temperature before the heating cycle is obtained using a secondary cryopump ( $\approx 14000 \mathrm{l} \mathrm{s}^{-1}$ through a $40 \mathrm{~cm}$ pumping orifice diameter) and primary dry pumps.

Inside the furnace, there are four locations (Fig. 1b) for temperature recordings using $\mathrm{K}$ type thermocouples. In the furnace gate a viewing port ( $0.07 \mathrm{~m}$ diameter) and apertures in thermal front shields allow visual observations and temperature determinations using a pyrometer. For the studied brazing cycle, the furnace is heated in two temperature ramps: - first a $5 \mathrm{~K}$ step per minute until $1068 \mathrm{~K}$ and then a temperature plateau is maintained $100 \mathrm{~min}$ - second a $3 \mathrm{~K}$ step per minute until $1163 \mathrm{~K}$ and a final temperature plateau for brazing is maintained $10 \mathrm{~min}$. After switching off heating and decreasing the temperature inside the furnace down to $998 \mathrm{~K}$ a nitrogen gas is flushed (99.95\%) $\left(\mathrm{H}_{2} \mathrm{O}<10\right.$ ppm, $\left.\mathrm{O}_{2}<10 \mathrm{ppm}\right)$ in the furnace close to one atmosphere and vented using a stator-less turbine located at the rear aperture of the casing in order to increase the cooling rate of the load. 


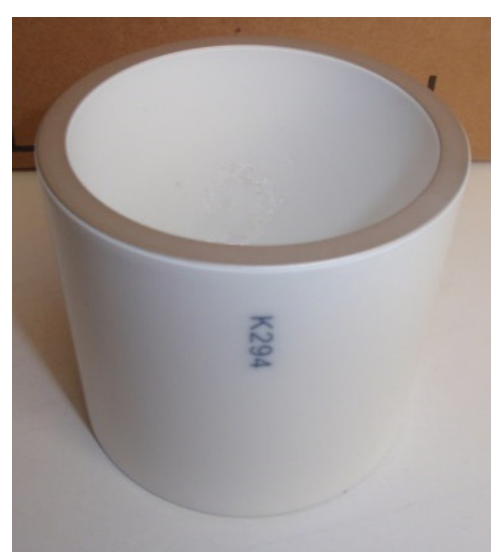

(a)

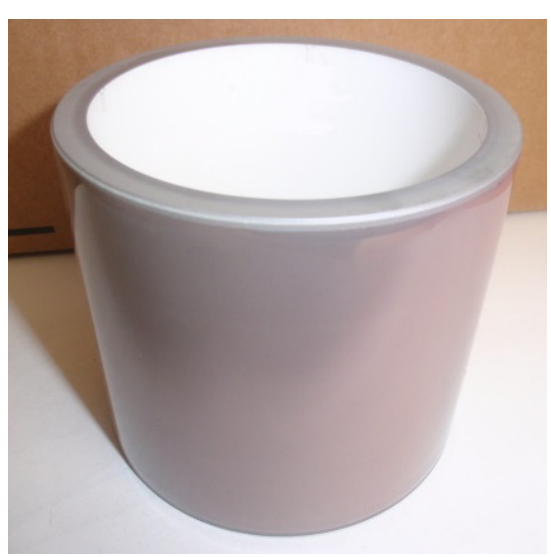

(b)

Fig. 3. Insulators $\left(\mathrm{Al}_{2} \mathrm{O}_{3}\right)$ of VCB: (a) original insulator part before brazing process; (b) insulator with deposits after brazing process.

\subsection{Characterization of oxides deposits}

Two types of deposit morphologies on insulators may be observed after a brazing cycle: (i) a red to gray or green gradual coloured deposit as presented in Figure 3 that can be more or less easily hand-cleaned with a stuff and, (ii) an strongly adhesive metallic mirror deposit.

In the first and currently case, the EDXray microanalysis on samples without deposits (see Figs. 3 and $4 b$ ) reveals the presence of Silicon (45.3 at \%), Aluminum (19.0 at\%), and Oxygen (24.2 at\%), characteristics of the alumina ceramic and silica based glaze. The presence of Potassium (5.6 at \%), Sodium (1.9 at\%), Magnesium (1.3 at\%), Calcium ( 1 at $\%$ ) and Manganese $(0.5$ at $\%)$ is justified by the method of preparation of ceramics and its glazing. For sample with visible deposits (see Fig. 3b) and according to the spectra after removing the above contributions of substrate chemical species, the deposit is characterized by the major presence of Copper (2.5 at $\%)$, a small contribution of Molybdenum (1.7 at \%), and some traces of Iron (0.5 at \%).

The second case is related to some rare brazing cycles which were associated to overheating of the supplementary central resistor since the deposit analysed by MEB (see Fig. 4a) revealed some small like-droplets at the surface - or probably crystal growth structures - and the EDX analysis (see
Fig. $4 \mathrm{~b})$ shows the only contribution of pure molybdenum.

\subsection{Thermodynamic data and calculation method}

The casing in which is performed the brazing process is a closed thermal shield housing with the only two apertures (described before) and it can be considered analogous to a Knudsen effusion cell - a basic vessel to study high temperature equilibrium vaporization processes [4] - with the ratio s/S between the cross-section " $s$ " of the effusion orifice located in its lid and the surface "S" of the vaporizing sample disposed inside the cell. This ratio is usually taken $\leq 10^{-2}$ [5] in order to obtain equilibrium conditions for vaporisation of surfaces at least when reactions of vaporisation are fast enough (evaporation coefficient of metals, usually, is $>0.1$ ). Here, the orifices for gas or vapours effusion out of the casing are the front aperture facing the viewing port (fitted with retractable thermal shields as explained before) and the rear aperture (fitted with a stator-less turbine for venting the cooling gas). The "equivalent" sample vaporizing surface in the brazing furnace is all the surfaces of different parts of Vis which vaporize from one furnace load during the brazing process. In Table 1, the only surfaces which are presented are the VI inner and outer surfaces "exposed to vacuum" inside the furnace volume, excluding for example the hidden surfaces in contact 


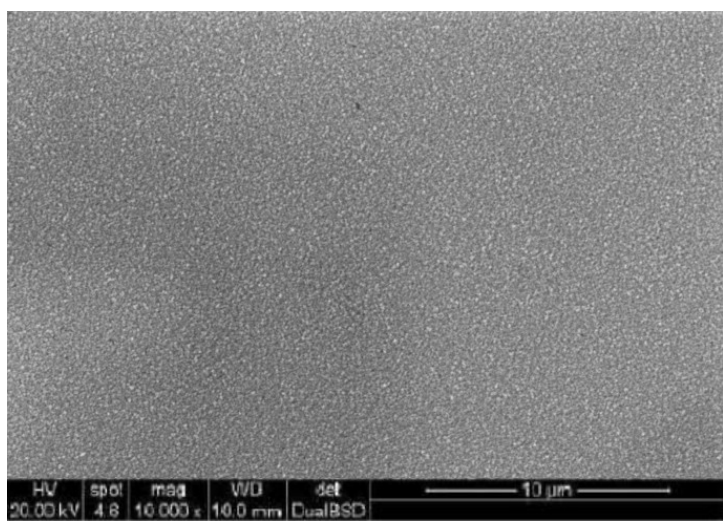

(a)

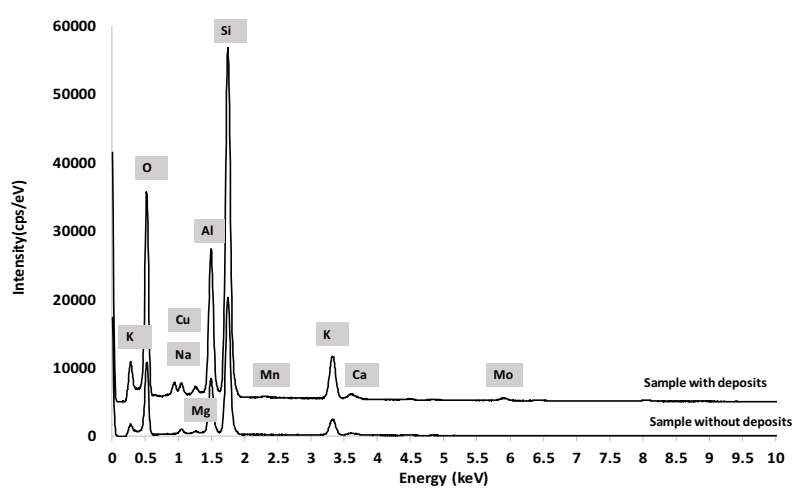

(b)

Fig. 4. (a) Scanning electron micrograph of a sample with deposits on ceramic parts which were associated to overheating of a supplementary central resistor. (b) The representative EDX spectra of a sample without deposits and for one with deposits on ceramic parts.

Table 1. Vaporization and condensation surfaces in the brazing oven which are taken into account for flow calculations.

\begin{tabular}{|c|c|c|c|c|c|}
\hline \multicolumn{2}{|c|}{ Components of VCB } & $\begin{array}{c}\text { Surface } \\
\text { exposed } \\
\text { to vacuum } \\
/ \mathrm{m}^{2}\end{array}$ & $\begin{array}{c}\text { Ratio } s / S \\
\text { Escaping } \\
\text { flow/evaporation } \\
\text { flows }\end{array}$ & $\begin{array}{c}\text { Surface } \\
\text { exposed to } \\
\text { vacuum } \\
/ \%\end{array}$ & $\begin{array}{c}\text { Total surface } \\
\text { per load that } \\
\text { vaporizes } \\
/ \mathrm{m}^{2}\end{array}$ \\
\hline \multicolumn{2}{|c|}{ Conductors (Cu OFHC) } & 1.8 & 0.003 & 27.9 & \\
\hline \multicolumn{2}{|c|}{ Contacts (Cu-Cr alloy) } & 0.576 & 0.0094 & 8.9 & \\
\hline \multicolumn{2}{|c|}{ Flanges - bowls (Cu-Ni alloy) } & 3.96 & 0.0014 & 61.3 & \\
\hline \multirow{4}{*}{$\begin{array}{l}\text { brazed joints } \\
\text { (Cu-Ag-Ni alloy) }\end{array}$} & $\begin{array}{c}\text { conductors } \\
\text { with bellows } \\
\text { shields }\end{array}$ & 0.029 & & 1.9 & 6.458 \\
\hline & $\begin{array}{l}\text { bellows with } \\
\text { bellows } \\
\text { shields. }\end{array}$ & 0.058 & 0.044 & & \\
\hline & $\begin{array}{l}\text { insulator with } \\
\text { flange }\end{array}$ & 0.029 & & & \\
\hline & $\begin{array}{l}\text { bellows with } \\
\text { flange }\end{array}$ & 0.006 & & & \\
\hline $\begin{array}{c}\text { Casing } \\
\text { deposit } \\
\text { (mainly } \\
\text { Ag-Cu alloy) }\end{array}$ & $\begin{array}{c}\text { First Mo } \\
\text { thermal } \\
\text { shield }\end{array}$ & 6.154 & 0.0008 & 100 & 6.154 \\
\hline \multicolumn{2}{|c|}{ Resistor $(\mathrm{Mo})$} & 5.197 & 0.001 & 200 & 5.197 \\
\hline \multirow[b]{2}{*}{$\begin{array}{l}\text { Apertures of the } \\
\text { casing }\end{array}$} & $\begin{array}{c}\text { Front } \\
\text { aperture }\end{array}$ & 0.0004 & & & 0.0054 \\
\hline & $\begin{array}{l}\text { Rear aperture } \\
\text { (fitted with } \\
\text { the turbine) }\end{array}$ & 0.005 & & & \\
\hline
\end{tabular}


at the brazed interfaces. The above criter

$3 \quad\left(s / S<10^{-2}\right)$ for equilibrium vaporization in

4 the casing is fulfilled as presented in Table 1.

Matter flow vaporization and condensation calculations are performed considering that a thermodynamic equilibrium is established between the condensed sample i.e. each loaded part surface and its vapour phase - and the casing volume. Due to some condensation on the casing first thermal shield - which is the first cold temperature encountered by the vaporizing flows - the internal surface of the casing is taken into account for the vaporization of these deposits. All surfaces are considered to vaporize at equilibrium since the balance of evaporating and condensing flows are close to 1 , except for molybdenum based gaseous species that may come from the resistor and vaporize at higher temperature than the casing and the load temperature and this feature let these species condense instantaneously Consequently no molybdenum species back flow on the resistor can occur and the Mo and related species vaporization is considered as free vaporization. For free vaporization it may exist a "so-called" evaporation coefficient [6] usually quoted as $\alpha_{\mathrm{i}}$ ( $i$ for each gaseous species). At equilibrium this coefficient equals 1 but in case of some low kinetic process at vaporization $\alpha_{\mathrm{i}}<1$ and sometimes very low for complex species $\left(\approx 10^{-4}\right.$ to $10^{-6}$ ) vaporizing from some condensed phases as amorphous. However we shall consider that these species evaporate at equilibrium for molybdenum or molybdenum oxide which corresponds to the maximum vaporization rate.

The SGTE-Alloy Phase Diagrams Thermodynamic database [7] - a database where the basic binary alloys corresponding to the VI parts are stored - was used to calculate the gaseous phase formed during the brazing process, and it was operated with the FactSage [8] software with "Equilib module" which performs the thermochemical equilibrium calculations based on Gibbs energy minimization. Because oxygen combination with the present alloys components is the main key point of this study, we completed SGTE alloys phase diagrams information with the following binary and ternary sys- tems the thermodynamic and phase diagram data of which were already optimized in scientific literature: $\mathrm{Cu}-\mathrm{O}[9,10], \mathrm{Ag}-\mathrm{O}[9,11]$ $\mathrm{Cr}-\mathrm{O}$ [12] , Ni-O [13], Cu-Ag-Ni [14], and $\mathrm{Cu}-\mathrm{Ag}-\mathrm{O}[15]$

For an alloy composed by an homogeneous phase or for diphasic systems like $\mathrm{Mo}(\mathrm{s})-\mathrm{MoO}_{2}(\mathrm{~s})$ as an example, the partial vapour pressure of the $j$ gaseous species is related to temperature by the simple relation,

$$
\ln p_{j}=-\frac{\Delta_{\text {vap }} H_{j}(\bar{T})}{R T}+\Delta_{\text {vap }} S_{j}(\bar{T})
$$

in which the partial enthalpy $\Delta_{\text {vap }} H_{j}(\bar{T})$ and entropy $\Delta_{\text {vap }} S_{j}(\bar{T})$ of vaporization of the $j$ molecule at mean temperature are constants in our temperature range. For this reason, we used the final relation for partial pressures calculations as,

$$
\log _{10} p_{j}=\frac{A}{T}+B
$$

In case of phase change - as for braze melting - a new relation is used for the new phase in the temperature range where this phase is stable. The whole set of known gaseous species vapour pressures and related coefficients are summarized in Table 2.

Those partial pressures relations were then introduced in Visual Basic from Excel (Microsoft Office Package) in order to calculate the different matter flows and to solve flow balances. The molar flow $\mathrm{Fj}$ of any $j$ gaseous molecule (i.e. $\mathrm{Cu}, \mathrm{Cu}_{2}, \mathrm{Cr}, \mathrm{CrO}$, $\mathrm{CrO}_{2}, \mathrm{Ag}, \mathrm{Ni}, \mathrm{O}, \mathrm{O}_{2}$, etc.) vaporized from each part surface exposed to vacuum during one brazing cycle was calculated along any temperature cycle using the equation for steady-state effusion of dilute gases in vacuum, known as the Hertz-Knudsen relation [4] :

$$
F_{j}=\frac{\alpha_{j} p_{j} S_{\text {vap }}}{\sqrt{2 \pi M_{j} R T}} \Delta t
$$

where:

$F_{i}$ - is the molar flow of $j$ molecule $\left(\mathrm{mol} \cdot \mathrm{m}^{-2} \cdot \mathrm{s}^{-1}\right)$;

$\Delta t$ - is the cycle time unit (in s) selected from temperature recordings: here $30 \mathrm{~s}$;

$\alpha_{j}$ - the evaporation coefficient we set equal to 1 for equilibrium conditions (see text above); 
I Nuta et al.: Metall. Res. Technol.

Table 2. Coefficients for the calculation of partial pressures of vaporization as a function of the inverse of temperature for the different parts materials i.e. conductors, contacts, flanges brazing joints and resistor (Mo). Their behaviour with temperature is given as $\log _{10}(p / P a)=A /(T / K)+B$.

\begin{tabular}{|c|c|c|c|c|}
\hline $\begin{array}{l}\text { VCB parts } \\
\text { and } \\
\text { material }\end{array}$ & $\begin{array}{l}\text { Gaseous } \\
\text { Species }\end{array}$ & $\mathrm{A}$ & $B$ & $\begin{array}{c}\text { Temperature range } \\
/ / \mathrm{K}\end{array}$ \\
\hline $\begin{array}{c}\text { Conductors } \\
\text { OFHC Cu } \\
\text { Pure Cu }\end{array}$ & $\begin{array}{l}\mathrm{Cu}(\mathrm{g}) \\
\mathrm{Cu}_{2}(\mathrm{~g})\end{array}$ & $\begin{array}{l}-17559 \\
-24523\end{array}$ & $\begin{array}{l}11.7163 \\
13.4940\end{array}$ & $300-1300$ \\
\hline $\begin{array}{c}\text { Contacts } \\
\text { Molar fractions } \\
X_{\mathrm{Cu}}=0.71 \\
X_{\mathrm{Cr}}=0.29 \\
\text { alloy }\end{array}$ & $\begin{array}{l}\mathrm{Cu}(\mathrm{g}) \\
\mathrm{Cu}_{2}(\mathrm{~g}) \\
\mathrm{Cr}(\mathrm{g}) \\
\mathrm{Cr}_{2}(\mathrm{~g})\end{array}$ & $\begin{array}{l}-17558 \\
-24520 \\
-21898 \\
-32658\end{array}$ & $\begin{array}{l}11.7139 \\
13.4891 \\
13.4678 \\
14.5295\end{array}$ & $300-1300$ \\
\hline $\begin{array}{c}\text { Flanges/bowls } \\
\text { Molar fractions } \\
X_{\mathrm{Cu}}=0.68 \\
X_{\mathrm{N}} \mathrm{i}=0.32 \\
\text { alloy }\end{array}$ & $\begin{array}{c}\mathrm{Cu}(\mathrm{g}) \\
\mathrm{Cu}_{2}(\mathrm{~g}) \\
\mathrm{Ni}(\mathrm{g}) \\
\mathrm{Ni}_{2}(\mathrm{~g})\end{array}$ & $\begin{array}{l}-17518 \\
-24440 \\
-21800 \\
-33324\end{array}$ & $\begin{array}{l}11.5597 \\
13.1807 \\
12.2498 \\
13.7763\end{array}$ & $300-1300$ \\
\hline $\begin{array}{c}\text { Solder } \\
\text { Molar fractions } \\
X_{\mathrm{Cu}}=0.3967 \\
X_{\mathrm{Ag}}=0.5918 \\
X_{\mathrm{Ni}}=0.0115 \\
\text { Solid alloy }\end{array}$ & $\begin{array}{c}\mathrm{Ag}(\mathrm{g}) \\
\mathrm{Ag}_{2}(\mathrm{~g}) \\
\mathrm{Cu}(\mathrm{g}) \\
\mathrm{Cu}_{2}(\mathrm{~g}) \\
\mathrm{Ni}(\mathrm{g}) \\
\mathrm{Ni}_{2}(\mathrm{~g}) \\
\mathrm{AgCu}(\mathrm{g})\end{array}$ & $\begin{array}{l}-14812 \\
-21014 \\
-17580 \\
-24535 \\
-21962 \\
-33656 \\
-23393\end{array}$ & $\begin{array}{l}6.6009 \\
8.3602 \\
6.7545 \\
8.5380 \\
7.6329 \\
9.5469 \\
8.7764 \\
\end{array}$ & $\begin{array}{c}300-1240 \\
\text { (solid phase) }\end{array}$ \\
\hline $\begin{array}{c}\text { Solder } \\
\text { Molar fractions } \\
X_{\mathrm{Cu}}=0.3967 \\
X_{\mathrm{Ag}}=0.5918 \\
X_{\mathrm{Ni}}=0.0115 \\
\text { Liquid alloy }\end{array}$ & $\begin{array}{c}\mathrm{Ag}(\mathrm{g}) \\
\mathrm{Ag}_{2}(\mathrm{~g}) \\
\mathrm{Cu}(\mathrm{g}) \\
\mathrm{Cu}_{2}(\mathrm{~g}) \\
\mathrm{Ni}(\mathrm{g}) \\
\mathrm{Ni}_{2}(\mathrm{~g}) \\
\mathrm{AgCu}(\mathrm{g})\end{array}$ & $\begin{array}{l}-13915 \\
-19094 \\
-17316 \\
-23919 \\
-21689 \\
-33176 \\
-22093\end{array}$ & $\begin{array}{l}10.8224 \\
11.6741 \\
11.4929 \\
12.9368 \\
12.3601 \\
14.0645 \\
12.5945\end{array}$ & $\begin{array}{c}1240-1300 \\
\text { (liquid phase) }\end{array}$ \\
\hline $\begin{array}{c}\text { Deposits } \\
\mathrm{Ag}_{0.97}-\mathrm{Cu}_{0.03} \\
\text { alloy } \\
\text { /mol. Frac. }\end{array}$ & $\begin{array}{c}\mathrm{Ag}(\mathrm{g}) \\
\mathrm{Ag}_{2}(\mathrm{~g}) \\
\mathrm{Cu}(\mathrm{g}) \\
\mathrm{Cu}_{2}(\mathrm{~g}) \\
\mathrm{AgCu}(\mathrm{g})\end{array}$ & $\begin{array}{l}-14820 \\
-21036 \\
-17594 \\
-24610 \\
-23421 \\
\end{array}$ & $\begin{array}{l}11.6353 \\
13.4534 \\
11.8021 \\
13.7119 \\
13.8845 \\
\end{array}$ & $\begin{array}{c}400-1020 \\
(\mathrm{Cu}-\mathrm{Ag} \text { sol. })\end{array}$ \\
\hline $\begin{array}{c}\text { Deposits } \\
\mathrm{Ag}_{0.97}-\mathrm{Cu}_{0.03} \\
\text { alloy } \\
\text { /mol. Frac. }\end{array}$ & $\begin{array}{c}\mathrm{Ag}(\mathrm{g}) \\
\mathrm{Ag}_{2}(\mathrm{~g}) \\
\mathrm{Cu}(\mathrm{g}) \\
\mathrm{Cu}_{2}(\mathrm{~g}) \\
\mathrm{AgCu}(\mathrm{g})\end{array}$ & $\begin{array}{l}-14661 \\
-20636 \\
-15834 \\
-21006 \\
-21414 \\
\end{array}$ & $\begin{array}{l}6.4220 \\
7.9164 \\
4.5497 \\
4.0942 \\
6.3007 \\
\end{array}$ & $\begin{array}{c}1020-1120 \\
\text { (liquid phase) }\end{array}$ \\
\hline $\begin{array}{c}\text { Deposits } \\
\mathrm{Ag}_{0.97}-\mathrm{Cu}_{0.03} \\
\text { alloy } \\
\text { /mol. Frac. }\end{array}$ & $\begin{array}{c}\mathrm{Ag}(\mathrm{g}) \\
\mathrm{Ag}_{2}(\mathrm{~g}) \\
\mathrm{Cu}(\mathrm{g}) \\
\mathrm{Cu}_{2}(\mathrm{~g}) \\
\mathrm{AgCu}(\mathrm{g})\end{array}$ & $\begin{array}{l}-13911 \\
-19085 \\
-15700 \\
-20687 \\
-20472\end{array}$ & $\begin{array}{l}5.8060 \\
6.6407 \\
4.1426 \\
3.2355 \\
5.2270 \\
\end{array}$ & $\begin{array}{c}1120-1300 \\
\text { (liquid phase) }\end{array}$ \\
\hline $\begin{array}{c}\text { OFHC Cu- } \\
\mathrm{Cu}_{2} \mathrm{O}\end{array}$ & $\begin{array}{c}\mathrm{Cu}(\mathrm{g}) \\
\mathrm{Cu}_{2}(\mathrm{~g}) \\
\mathrm{CuO}(\mathrm{g}) \\
\mathrm{O}_{2}(\mathrm{~g}) \\
\mathrm{O}(\mathrm{g}) \\
\mathrm{O}_{3}(\mathrm{~g})\end{array}$ & $\begin{array}{l}-17544.4 \\
-24482.1 \\
-24940.7 \\
-17703.3 \\
-21979.5 \\
-33971.7\end{array}$ & $\begin{array}{l}6.7027 \\
8.4557 \\
8.7874 \\
7.7173 \\
7.1872 \\
8.0012 \\
\end{array}$ & $400-1300 \mathrm{~K}$ \\
\hline
\end{tabular}


I Nuta et al.: Metall. Res. Technol.

Table 2. Continued.

\begin{tabular}{|c|c|c|c|c|}
\hline $\begin{array}{c}\text { Flanges/Bowls } \\
X_{\mathrm{Cu}}=0.68 \\
X_{\mathrm{Ni}}=0.32 \\
+\mathrm{NiO}\end{array}$ & $\begin{array}{c}\mathrm{Cu}(\mathrm{g}) \\
\mathrm{Cu}_{2}(\mathrm{~g}) \\
\mathrm{Ni}(\mathrm{g}) \\
\mathrm{Ni}_{2}(\mathrm{~g}) \\
\mathrm{CuO}(\mathrm{g}) \\
\mathrm{NiO}(\mathrm{g}) \\
\mathrm{O}_{2}(\mathrm{~g}) \\
\mathrm{O}(\mathrm{g}) \\
\mathrm{O}_{3}(\mathrm{~g})\end{array}$ & $\begin{array}{l}-17540.8 \\
-24518.3 \\
-21975.9 \\
-33676.2 \\
-28551.6 \\
-27283.7 \\
-24936.0 \\
-25541.4 \\
-44795.2\end{array}$ & $\begin{array}{c}6.6206 \\
8.3807 \\
7.6642 \\
9.5979 \\
9.6320 \\
9.6248 \\
9.5790 \\
8.0057 \\
10.7426 \\
\end{array}$ & $400-564 \mathrm{~K}$ \\
\hline $\begin{array}{c}\text { Flanges/Bowls } \\
X_{\mathrm{Cu}}=0.68 \\
X_{\mathrm{Ni}}=0.32 \\
+\mathrm{NiO}\end{array}$ & $\begin{array}{c}\mathrm{Cu}(\mathrm{g}) \\
\mathrm{Cu}_{2}(\mathrm{~g}) \\
\mathrm{Ni}(\mathrm{g}) \\
\mathrm{Ni}_{2}(\mathrm{~g}) \\
\mathrm{CuO}(\mathrm{g}) \\
\mathrm{NiO}(\mathrm{g}) \\
\mathrm{O}_{2}(\mathrm{~g}) \\
\mathrm{O}(\mathrm{g}) \\
\mathrm{O}_{3}(\mathrm{~g})\end{array}$ & $\begin{array}{l}-17462.8 \\
-24286.8 \\
-21636.1 \\
-33015.6 \\
-28528.1 \\
-26899.8 \\
-25041.2 \\
-25686.9 \\
-45001.8\end{array}$ & $\begin{array}{c}6.4967 \\
8.0071 \\
7.0711 \\
8.4398 \\
9.6215 \\
8.9792 \\
9.7978 \\
8.2710 \\
11.1490\end{array}$ & $564-1400 \mathrm{~K}$ \\
\hline $\begin{array}{c}\text { Contact pads } \\
(\mathrm{Cu}, \mathrm{Cr}, \mathrm{O})- \\
\mathrm{Cr}_{2} \mathrm{O}_{3}\end{array}$ & $\begin{array}{c}\mathrm{Cu}(\mathrm{g}) \\
\mathrm{Cu}_{2}(\mathrm{~g}) \\
\mathrm{Cr}(\mathrm{g}) \\
\mathrm{Cr}_{2}(\mathrm{~g}) \\
\mathrm{CuO}(\mathrm{g}) \\
\mathrm{CrO}(\mathrm{g}) \\
\mathrm{CrO}_{2}(\mathrm{~g}) \\
\mathrm{CrO}_{3}(\mathrm{~g}) \\
\mathrm{Cr}_{2} \mathrm{O}(\mathrm{g}) \\
\mathrm{Cr}_{2} \mathrm{O}_{2}(\mathrm{~g}) \\
\mathrm{Cr}_{2} \mathrm{O}_{3}(\mathrm{~g}) \\
\mathrm{O}_{2}(\mathrm{~g}) \\
\mathrm{O}(\mathrm{g}) \\
\mathrm{O}_{3}(\mathrm{~g})\end{array}$ & $\begin{array}{c}-17471.8 \\
-24298.3 \\
-21797.6 \\
-32417.6 \\
-35700.9 \\
-29161.8 \\
-33457.5 \\
-42128.5 \\
-33480.0 \\
34070.7- \\
41775.0 \\
-39369.2 \\
-32858.3 \\
-66499.3\end{array}$ & $\begin{array}{c}6.6221 \\
8.2521 \\
8.35600 \\
9.2715 \\
9.2744 \\
9.8493 \\
10.2681 \\
9.83673 \\
11.0282 \\
10.8292 \\
12.9331 \\
8.8592 \\
7.8053 \\
9.7368\end{array}$ & $300-1348 \mathrm{~K}$ \\
\hline $\begin{array}{c}\text { Contact pads } \\
(\mathrm{Cu}, \mathrm{Cr}, \mathrm{O})- \\
\mathrm{Cr}_{2} \mathrm{O}_{3}\end{array}$ & $\begin{array}{c}\mathrm{Cu}(\mathrm{g}) \\
\mathrm{Cu}_{2}(\mathrm{~g}) \\
\mathrm{Cr}(\mathrm{g}) \\
\mathrm{Cr}_{2}(\mathrm{~g}) \\
\mathrm{CuO}(\mathrm{g}) \\
\mathrm{CrO}(\mathrm{g}) \\
\mathrm{CrO}_{2}(\mathrm{~g}) \\
\mathrm{CrO}_{3}(\mathrm{~g}) \\
\mathrm{Cr}_{2} \mathrm{O}(\mathrm{g}) \\
\mathrm{Cr}_{2} \mathrm{O}_{2}(\mathrm{~g}) \\
\mathrm{Cr}_{2} \mathrm{O}_{3}(\mathrm{~g}) \\
\mathrm{O}_{2}(\mathrm{~g}) \\
\mathrm{O}(\mathrm{g}) \\
\mathrm{O}_{3}(\mathrm{~g})\end{array}$ & $\begin{array}{l}-16400.3 \\
-22056.9 \\
-21389.9 \\
-31624.7 \\
-34541.5 \\
-28631.3 \\
-32892.0 \\
-41678.4 \\
-32497.4 \\
-33193.3 \\
-41037.1 \\
-39224.8 \\
-32884.0 \\
-66401.4\end{array}$ & $\begin{array}{c}5.8111 \\
6.5501 \\
8.0362 \\
8.6373 \\
8.3890 \\
9.4232 \\
9.8095 \\
9.4682 \\
10.2424 \\
10.1247 \\
12.3383 \\
8.7351 \\
7.8233 \\
9.6458\end{array}$ & $1348-1600 \mathrm{~K}$ \\
\hline $\begin{array}{l}(\mathrm{Ag}, \mathrm{Cu}, \mathrm{Ni}, \mathrm{O}) \\
-\mathrm{NiO} \text { solder }\end{array}$ & $\begin{array}{c}\mathrm{Ag}(\mathrm{g}) \\
\mathrm{Ag} 2(\mathrm{~g}) \\
\mathrm{Cu}(\mathrm{g}) \\
\mathrm{Cu} 2(\mathrm{~g}) \\
\mathrm{Ni}(\mathrm{g}) \\
\mathrm{AgCu}(\mathrm{g}) \\
\mathrm{CuO}(\mathrm{g}) \\
\mathrm{AgO}(\mathrm{g}) \\
\mathrm{NiO}(\mathrm{g}) \\
\mathrm{O} 2(\mathrm{~g}) \\
\mathrm{O}(\mathrm{g})\end{array}$ & & & Différentes phases \\
\hline
\end{tabular}


I Nuta et al.: Metall. Res. Technol.

Table 2. Continued.

\begin{tabular}{|c|c|c|c|c|}
\hline $\begin{array}{c}\mathrm{Ag}_{0.97}-\mathrm{Cu}_{0.03} \\
-\mathrm{Cu}_{2} \mathrm{O} \\
\text { Deposits }\end{array}$ & $\begin{array}{c}\mathrm{Ag}(\mathrm{g}) \\
\mathrm{Ag}_{2}(\mathrm{~g}) \\
\mathrm{Cu}(\mathrm{g}) \\
\mathrm{Cu}_{2}(\mathrm{~g}) \\
\mathrm{AgCu}(\mathrm{g}) \\
\mathrm{CuO}(\mathrm{g}) \\
\mathrm{AgO}(\mathrm{g}) \\
\mathrm{O}_{2}(\mathrm{~g}) \\
\mathrm{O}(\mathrm{g}) \\
\mathrm{O}_{3}(\mathrm{~g})\end{array}$ & $\begin{array}{c}-14787.6 \\
-20955.4 \\
-17566.9 \\
-24539.1 \\
-23345.2 \\
-24994.2 \\
-24484.2 \\
-17762.8 \\
-21996.645 \\
-34047.314\end{array}$ & $\begin{array}{l}6.5820 \\
8.3206 \\
6.7561 \\
8.5928 \\
8.7578 \\
8.9058 \\
8.9589 \\
7.8497 \\
7.2167 \\
8.1619\end{array}$ & $300-784 \mathrm{Kr}$ \\
\hline $\begin{array}{c}\mathrm{Ag}_{0.97}-\mathrm{Cu}_{0.03} \\
-\mathrm{Cu}_{2} \mathrm{O} \\
\text { Deposits }\end{array}$ & $\begin{array}{c}\mathrm{Ag}(\mathrm{g}) \\
\mathrm{Ag}_{2}(\mathrm{~g}) \\
\mathrm{Cu}(\mathrm{g}) \\
\mathrm{Cu}_{2}(\mathrm{~g}) \\
\mathrm{AgCu}(\mathrm{g}) \\
\mathrm{CuO}(\mathrm{g}) \\
\mathrm{AgO}(\mathrm{g}) \\
\mathrm{O}_{2}(\mathrm{~g}) \\
\mathrm{O}(\mathrm{g}) \\
\mathrm{O}_{3}(\mathrm{~g})\end{array}$ & $\begin{array}{l}-14663.9 \\
-20643.3 \\
-15856.7 \\
-21052.8 \\
-21441.5 \\
-26355.2 \\
-27431.8 \\
-23909.3 \\
-25145.8 \\
-43322.7\end{array}$ & $\begin{array}{c}6.4224 \\
7.9181 \\
4.5735 \\
4.1427 \\
6.3259 \\
10.6432 \\
12.7196 \\
15.6945 \\
11.2372 \\
20.0001\end{array}$ & $784-1200 \mathrm{~K}$ \\
\hline $\begin{array}{c}\mathrm{Ag}_{0.97}-\mathrm{Cu}_{0.03} \\
-\mathrm{Cu}_{2} \mathrm{O} \\
\text { Deposits }\end{array}$ & $\begin{array}{c}\mathrm{Ag}(\mathrm{g}) \\
\mathrm{Ag}_{2}(\mathrm{~g}) \\
\mathrm{Cu}(\mathrm{g}) \\
\mathrm{Cu}_{2}(\mathrm{~g}) \\
\mathrm{AgCu}(\mathrm{g}) \\
\mathrm{CuO}(\mathrm{g}) \\
\mathrm{AgO}(\mathrm{g}) \\
\mathrm{O}_{2}(\mathrm{~g}) \\
\mathrm{O}(\mathrm{g}) \\
\mathrm{O}_{3}(\mathrm{~g})\end{array}$ & $\begin{array}{l}-13717.0 \\
-18686.1 \\
-17570.1 \\
-24414.8 \\
-22133.6 \\
-24130.6 \\
-22545.3 \\
-16055.2 \\
-21282.4 \\
-31619.3\end{array}$ & $\begin{array}{c}5.6487 \\
6.3172 \\
5.6855 \\
6.3118 \\
6.6014 \\
9.1011 \\
9.2906 \\
10.4048 \\
8.6464 \\
12.1308\end{array}$ & $1218-1500 \mathrm{~K}$ \\
\hline $\begin{array}{c}\mathrm{Mo}(\mathrm{s})- \\
\mathrm{MoO}_{2}(\mathrm{~s})\end{array}$ & $\begin{array}{c}\mathrm{Mo}(\mathrm{g}) \\
\mathrm{O}(\mathrm{g}) \\
\mathrm{O}_{2}(\mathrm{~g}) \\
\mathrm{O}_{3}(\mathrm{~g}) \\
\mathrm{MoO}(\mathrm{g}) \\
\mathrm{MoO}_{2}(\mathrm{~g}) \\
\mathrm{MoO}_{3}(\mathrm{~g}) \\
\mathrm{Mo}_{2} \mathrm{O}_{6}(\mathrm{~g}) \\
\mathrm{Mo}_{3} \mathrm{O}_{9}(\mathrm{~g}) \\
\mathrm{Mo}_{4} \mathrm{O}_{12}(\mathrm{~g})\end{array}$ & $\begin{array}{l}-33948 \\
-28174 \\
-29830 \\
-33121 \\
-28543 \\
-25587 \\
-30073 \\
-36295 \\
-44062\end{array}$ & $\begin{array}{c}7.5034 \\
7.7433 \\
8.5864 \\
9.6700 \\
10.0078 \\
9.5608 \\
11.6708 \\
14.4155 \\
16.1263\end{array}$ & $1000-2000 \mathrm{~K}$ \\
\hline
\end{tabular}

$1 \quad p_{j}$-is the partial pressure of the molecule or gaseous species $j(\mathrm{~Pa})$;

$S_{\text {vap }}$ - is the vaporizing surface from one material in a load $\left(\mathrm{m}^{2}\right)$ (for more details see Tab. 1);

$R$ - is the ideal gas constant $=$ $8.3145 \mathrm{~J} \cdot \mathrm{mol}^{-1} \cdot \mathrm{K}^{-1}$;

$8 \mathrm{~T}$ - is temperature $(\mathrm{K})$;

$9 M_{j}-$ molar mass of the $j$ gaseous species o $\left(\mathrm{kg} \cdot \mathrm{mol}^{-1}\right)$.
During the vaporization and condensa- 11 tion processes, the only atomic flows $F_{i}$ for 12 any $i$ component are considered as issued 13 from different $j$ molecules and the following $\quad 14$ relation is used:

$$
F_{i}^{\text {evap }}=\sum_{j} v_{i} \frac{p_{j} S_{\text {vap }}}{\sqrt{2 \pi M_{j} R T}} \Delta t
$$

relation in which $v_{i}$ is the stoichiometric co- 16 efficient of the atom $i$ in the $j$ vaporized 17 


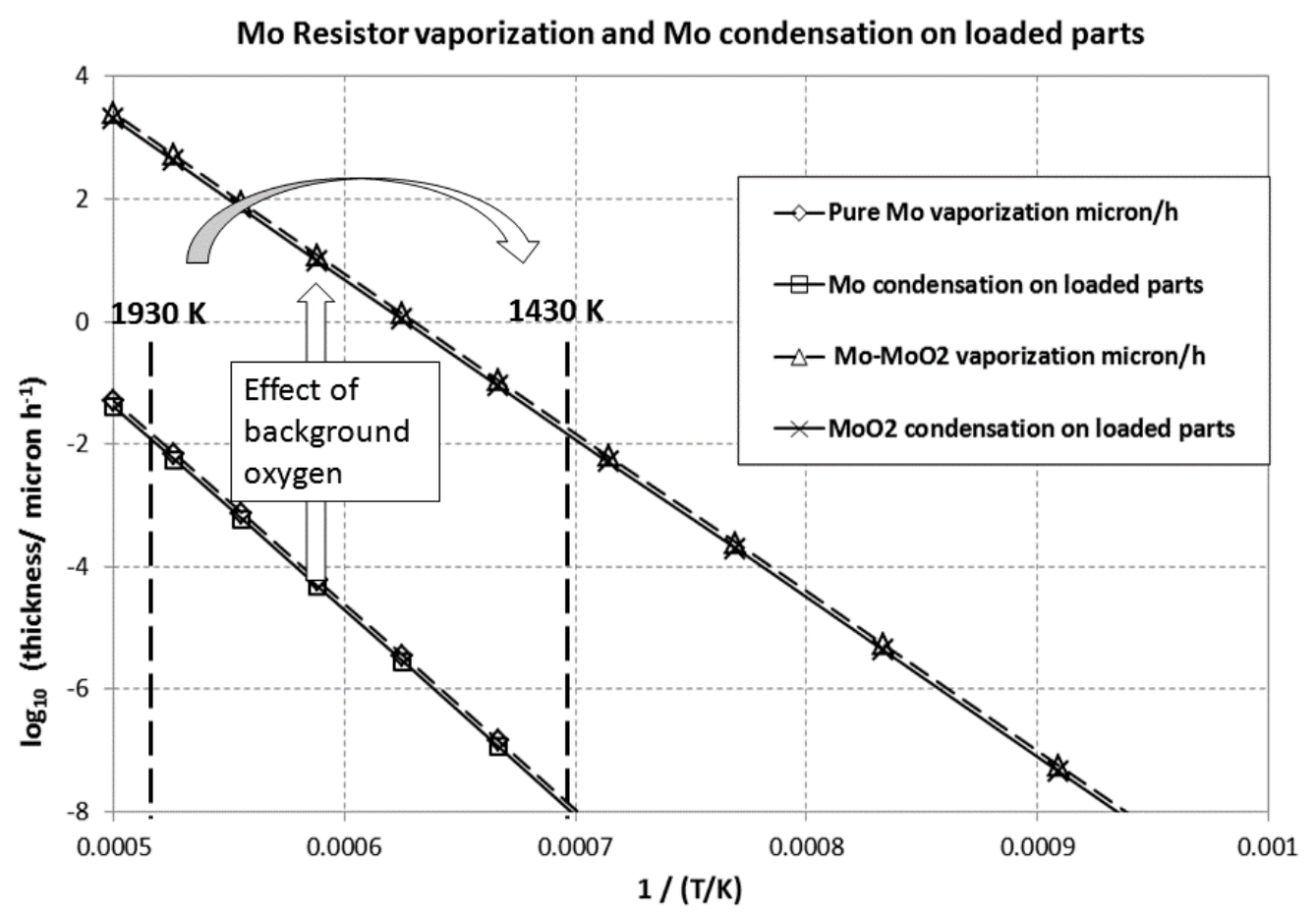

Fig. 5. Vaporization of the Mo resistor as pure Mo(g) under Ultra High Vacuum or Mo gaseous oxides when $\mathrm{MoO}_{2}(\mathrm{~s})$ is formed at its surface and condensation on loaded parts. The vaporization and condensation yield is presented as equivalent layers thickness in microns per hour

molecule. In case of condensation on another surface the same relation is applied, changing the surface value.

\section{Results related to the only vaporization of different materials}

\subsection{Vaporization flows of Mo from the resistor during one brazing cycle}

In a first step, the vaporization of the resistor is calculated with its associated Mo flows as a function of the resistor temperature since the maximum available temperature before the occurrence of Mo deposits in the casing is to be known in order to fix a limit to the electrical power input. The total evaporated Mo flow is calculated according to relation (4) at any temperature $T$ and total resistor surface available. This total vaporized flow may be condensed either on the casing first thermal shield - species emitted from the back surface of the Mo resistor - or on the loaded parts from the front surface of the Mo resistor. As these surfaces are at very low temperature compared to the resistor (at least $300 \mathrm{~K}$ gradient) the Mo species condense readily. The deposition on the first thermal shield made of Mo has no influence on other deposits as the Mo cannot be reemitted at the casing temperatures. Taking into account of the respective surfaces of the front surface of the resistor and the loaded parts, the deposit thickness can be evaluated using the respective surfaces as presented in Figure 5. As the surfaces ratio is close to 1 , the two curves for pure Mo vaporization and deposition are very close, the deposition thickness being slightly lower than the evaporation thickness.

However, in case of frontal situation between the resistor and some loaded parts - parts close to the resistor and deposits observed during some brazing cycles -, the ratio of evaporated surface to condensed surface becomes equal to 1 and the deposit thickness tends to be equal to the evaporation rate thickness. This represents the maximum deposit thickness as presented in Figure 5 for pure Mo. 
In case of increasing background oxygen pressure in the furnace and consequently in the casing via its two main orifices the Mo resistor may finally evaporate through several gaseous oxides the partial pressures of which increase with oxygen incident flow up to the apparition of the diphasic Mo$\mathrm{MoO}_{2}(\mathrm{~s})$ at the surface of the resistor. Taking into account of the formation of this diphasic at the surface of the resistor, same vaporization calculations are performed and reported as $\mathrm{MoO}_{2}(\mathrm{~s})$ deposits in Figure 5. The deposition rate increases by a factor $10^{4}$ to $10^{5}$ mainly due to the high volatility of molybdenum oxides. If a deposition limit is fixed at $10^{-2}$ micron $^{-1}$, the maximum available temperature for the Mo resistor in high vacuum is about $1930 \mathrm{~K}\left(1660{ }^{\circ} \mathrm{C}\right)$ meanwhile the oxygen background decreases this maximum temperature down to $1430 \mathrm{~K}\left(1160^{\circ} \mathrm{C}\right)$. Note that between the two situations - pure Mo vaporization and diphasic vaporization from the resistor material - intermediate steady-state vaporizations occur as calculated hereafter when considering the steadystate pumping of oxygen species between the casing and the furnace housing.

\subsection{Vaporization flows of loaded parts during one brazing cycle}

Among all parts existing in the industrial furnace our vaporization calculations take into account the only loaded parts because they are foreseen as major contributors to further deposits: conductors (Cu-OFHC), contacts ( $\mathrm{Cu}-\mathrm{Cr}$ alloys), flanges $(\mathrm{Cu}-\mathrm{Ni}$ alloys), and braze materials (Cu-Ag-Ni alloys) (refer to Tab. 2 for compositions). All gaseous species known and compiled in the data bank are used in the calculations, i.e. $\mathrm{Cu}(\mathrm{g})$, $\mathrm{Cu}_{2}(\mathrm{~g}), \mathrm{Cr}(\mathrm{g}), \mathrm{Cr}_{2}(\mathrm{~g}), \mathrm{Ni}(\mathrm{g}), \mathrm{Ni}_{2}(\mathrm{~g}), \mathrm{Ag}(\mathrm{g})$, $\mathrm{Ag}_{2}(\mathrm{~g})$ and $\mathrm{AgCu}(\mathrm{g})$. As the dimers and the hetero-atomic $\mathrm{AgCu}$ molecules have pressures lower than $10^{-3}$ times the monomer pressures, the evolution of partial pressures of the only main gaseous molecule versus the inverse of temperature are presented for all the present materials used to build a VI as coefficients in Table 1 and pressures in Figure 6. This inter-comparison of partial pressures over parts in the furnace shows that the same gaseous species originating from one pure material has higher pressures than from another alloyed part: - for instance $\mathrm{Cu}(\mathrm{g})$ pressure from conductors is higher than from braze even if the difference does not appear important - whereas some species like $\mathrm{Ag}(\mathrm{g})$ comes from the only braze material.

Consequently, some matter transport via the gaseous phase will occur during the brazing cycle between these different materials or parts. More, as the first thermal shield of the casing is at slightly lower temperature (measured as 10 to $20 \mathrm{~K}$ ) than the loaded parts, the vapours will go first to this cold point and partly condense and partly reevaporate. Another small proportion $\left(<10^{-2}\right)$ of vapours escapes by effusion through the two apertures of the casing. The main question is "what is the real pressure or the real partial pressures?" existing in the casing during the brazing cycle since thermodynamic calculations can be performed for only constant temperature and for a unique sample in its stable state. To understand what sort of steady-state is established in the casing during brazing we consider two limiting conditions:

1. For vaporization of parts with no matter back flow - open sky under vacuum or the casing assuming a total condensation of vapours (like a cold point at more than some $100 \mathrm{~K}$ below or induction furnace with cold thermal shields) the total flow of vaporization is calculated from the sum of parts vaporization flows. The mean flow molar fraction escaping from the parts during a brazing cycle has been calculated and is mainly $X_{\mathrm{Cu}}=0.39$ and $X_{\mathrm{Ag}}=0.61$ since other components are at very low partial pressures and their contribution is negligible.

2. For vaporization of parts under isothermal conditions - i.e. a first thermal shield of the casing at the same temperature as the loaded parts - the condensation flow coming back to the parts is the same as the vaporization flow, the only difference in the flows is coming from the two apertures that let escape a small effusing flow (same proportion as $s / S \leq 10^{-2}$ ). At that time quasi-equilibrium condi- 102 tions are established in the casing: par- 103 tial pressures are thus for each species 104 


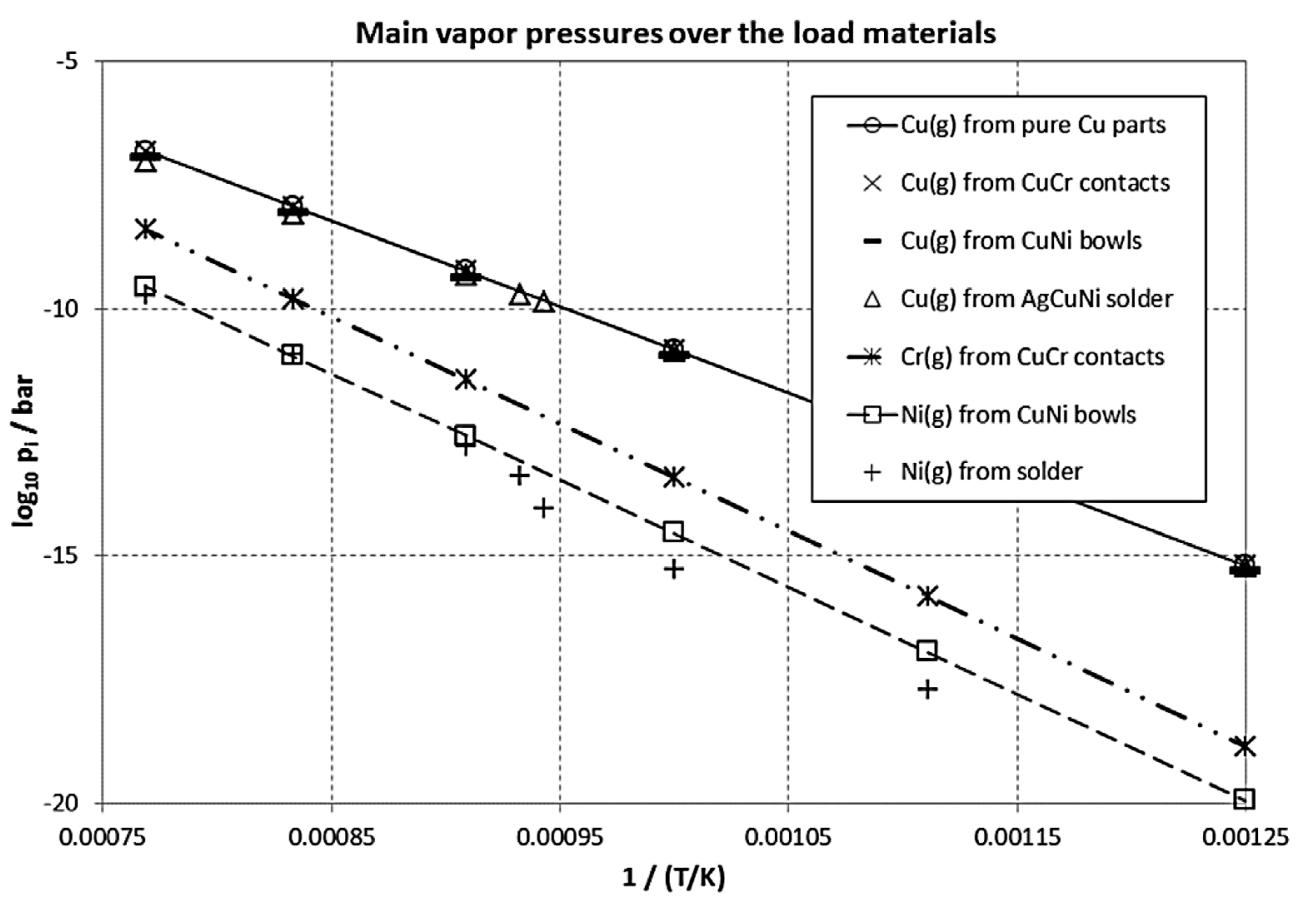

Fig. 6. Temperature-dependence of partial vapour pressures of gaseous species vaporizing from the different materials of the VCB. The only main gaseous species are presented: $\mathrm{Cu}(\mathrm{g})$ from conductors (pure $\mathrm{Cu}$ ), from $\mathrm{CuNi}$ bowls, from $\mathrm{CuCr}$ contacts and from the $\mathrm{AgCuNi}$ solder, $\mathrm{Cr}(\mathrm{g})$ from contacts, $\mathrm{Ni}(\mathrm{g})$ from bowls-flanges; $\mathrm{Ag}(\mathrm{g})$ from the solder material.

the partial pressure as calculated in Figure 6. But yet the partial pressures for any gaseous species cannot be summed and the value to be retained is the one coming from the main source material (i.e. the one with the greatest activity, i.e. pressure): for instance the $\mathrm{Ag}(\mathrm{g})$ pressure is controlled by the braze, the $\mathrm{Cu}(\mathrm{g})$ pressure controlled by the pure $\mathrm{Cu}$ parts. Indeed, parts made of alloys have activities lower than one (one is for pure components) and cannot generate higher pressures than pure components. For these alloyed parts, some incorporation of material can occur by adsorption from the vapour pressures in excess of their own ones and then followed by bulk diffusion to generate new alloys. Neglecting these phenomena that are considered to have low rates and not important for the duration of one brazing cycle, the gas phase composition is readily calculated from the only maximal partial pressures as,

See equations (5) and (6) next page.

taking into account of the only main components $\mathrm{Cu}$ and $\mathrm{Ag}$ in the vaporization process.
The resulting gas phase composition (molar fraction $X_{\mathrm{Ag}}$ of $\mathrm{Ag}$, with $\left.X_{\mathrm{Cu}}=1-X_{\mathrm{Ag}}\right)$ is presented in Figure 7 showing a composition very rich in $\mathrm{Ag}$ (like pure $\mathrm{Ag}$ ) at low temperature that becomes an alloy $(\mathrm{Ag}, \mathrm{Cu})$ with small $\mathrm{Cu}$ content (1 to $2 \%$ mole fraction) and a very small content with $\mathrm{Ni}$ and $\mathrm{Cr}$ (like impurities). This composition corresponds to quasi-equilibrium conditions that are established in the casing for the vapours.

During a brazing cycle, the first thermal shield temperature is measured along any brazing cycle to be slightly lower than the load temperature and the present gaseous phase (item 2 above) at quasi-equilibrium will partly condense on this shield and re-evaporate causing a matter back flow towards the loaded parts which becomes different from the one at equilibrium temperature of the loaded parts. Thermodynamic calculations of the phase composition condensed on the shield as well as its re-vaporization is performed starting from the above gas phase composition (isothermal conditions as for item 2) and decreasing the temperature by 0,10 and $20 \mathrm{~K}$ for 
I Nuta et al.: Metall. Res. Technol.

and

$$
X_{\mathrm{Cu}}=\frac{p_{\mathrm{Cu}}^{\text {conductors }}+2 p_{\mathrm{Cu}_{2}}^{\text {conductors }}}{p_{\mathrm{Cu}}^{\text {conductors }}+2 p_{\mathrm{Cu} 2}^{\text {conductors }}+p_{\mathrm{Ag}}^{\text {solder }}+2 p_{\mathrm{Ag}_{2}}^{\text {solder }}+p_{\mathrm{AgCu}}^{\text {solder }}}
$$

$$
X_{\mathrm{Ag}}=\frac{p_{\mathrm{Ag}}^{\text {solder }}+2 p_{\mathrm{Ag}_{2}}^{\text {solder }}+p_{\mathrm{AgCu}}^{\text {solder }}}{p_{\mathrm{Cu}}^{\text {conductors }}+2 p_{\mathrm{Cu}_{2}}^{\text {conductors }}+p_{\mathrm{Ag}}^{\text {solder }}+2 p_{\mathrm{Ag}_{2}}^{\text {solder }}+p_{\mathrm{AgCu}}^{\text {solder }}}
$$

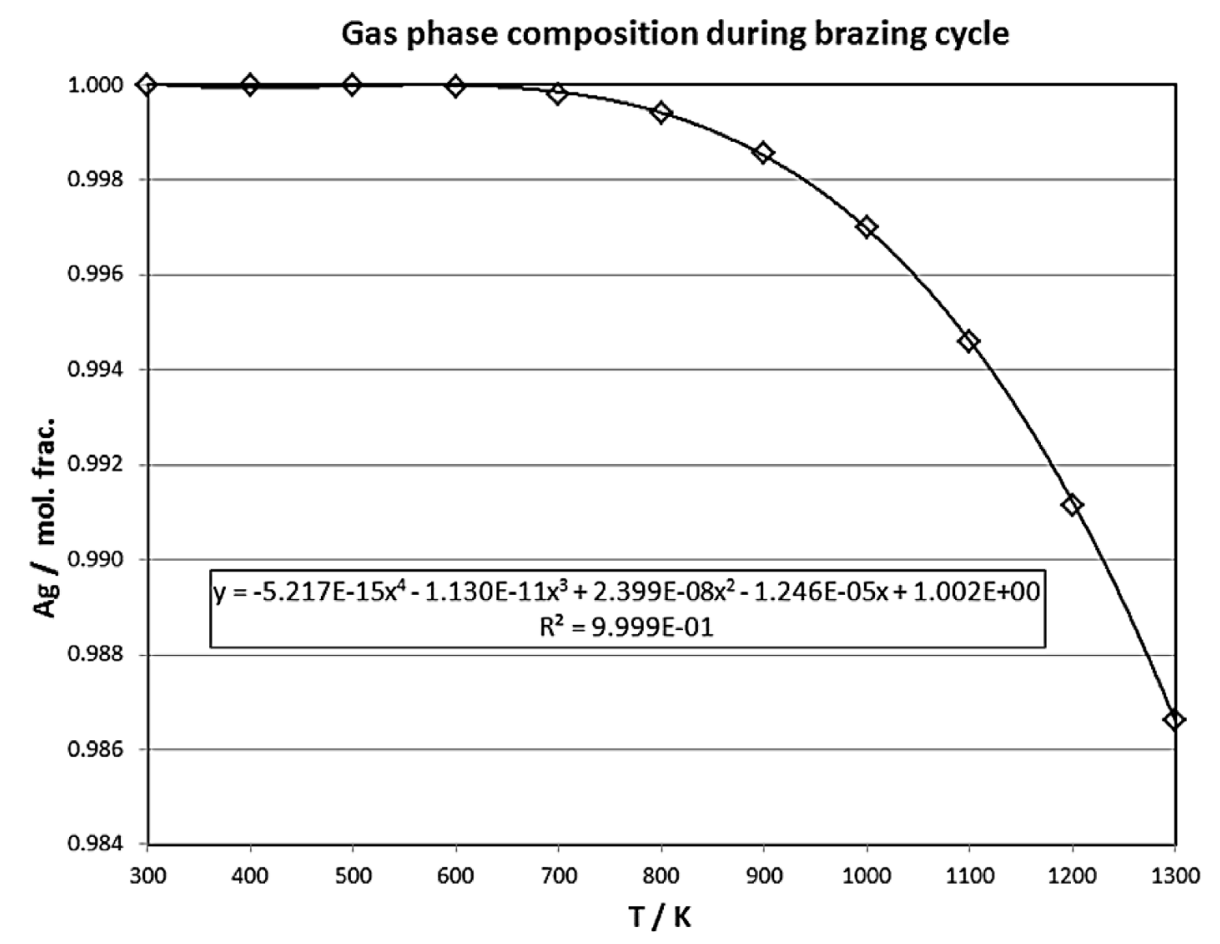

Fig. 7. Gas phase composition - molar fraction of Ag in the practically pure [Ag-Cu] system - issued from the vaporization of the loaded parts in the casing during one brazing cycle as a function of temperature of the load.

1 brazing cycle temperatures in the range 900 to $1300 \mathrm{~K}$ (in this range partial pressures are high enough to generate matter flows). The composition of the deposit is presented in Figure 8 and the ratio of condensed phase on the casing inner wall to vapour phase ratio (partition coefficient) in Figure 7.

In Figure 8, for a $0 \mathrm{~K}$ gradient (isothermal conditions) the sampled gas phase should not precipitate a condensed phase but here it precipitates because the original gas phase composition is not an equilibrium one - i.e. this phase results from a mixing of $\mathrm{Cu}+$ $\mathrm{AgCu}$ different vaporizing materials, and there is an excess of $\mathrm{Cu}(\mathrm{g})$ molecules. This feature explains the low values of the $\mathrm{Ag}$ concentration observed for $0 \mathrm{~K}$ gradient (on the $y$ axis). When a temperature gradient is established the condensed composition re- cover a value close to the one calculated in the above condition of quasi-equilibrium (inlet flow in the thermodynamic calculations). The composition of the deposit on the casing is close to the vapour one, a little bit richer with Ag. In Figure 9 the partition coefficient corresponds to the proportion of condensed phase reported to the gas phase (as a matter flow) as a function of the temperature gradient between the furnace and the first thermal (inner) shield of the casing. At high temperature the condensed phase on the casing becomes liquid for small gradients and this feature explains the apparent re-increasing value at $0 \mathrm{~K}$ gradient for $1300 \mathrm{~K}$. The knowledge of partition coefficient value allows the estimate of the total matter condensed on $1 \mathrm{~m}^{2}$ of casing during one brazing cycle from the incident Knudsen 
I Nuta et al.: Metall. Res. Technol.

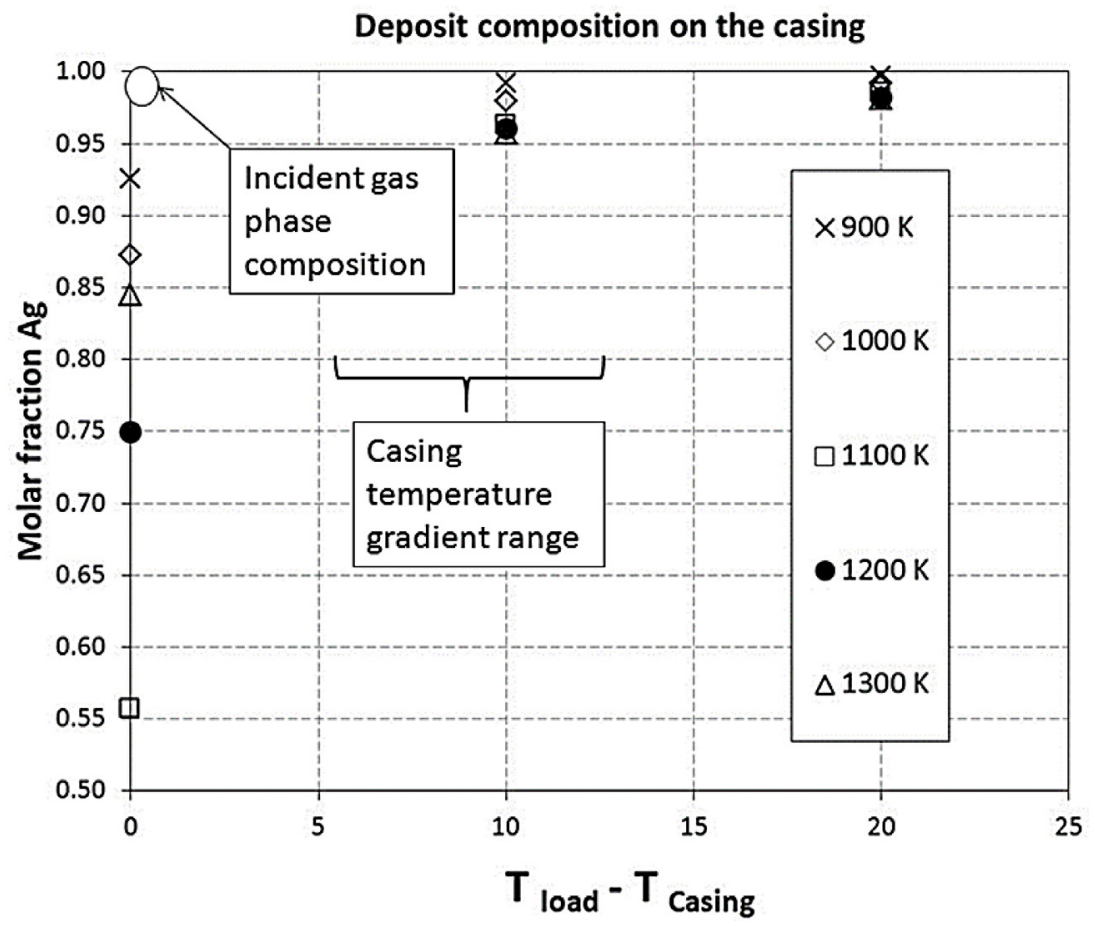

Fig. 8. Composition of the deposits - practically in the pure [Ag-Cu] binary system - on the first inner thermal shield of the casing as a function of the temperature gradient between the load and this shield for different treatment temperatures.

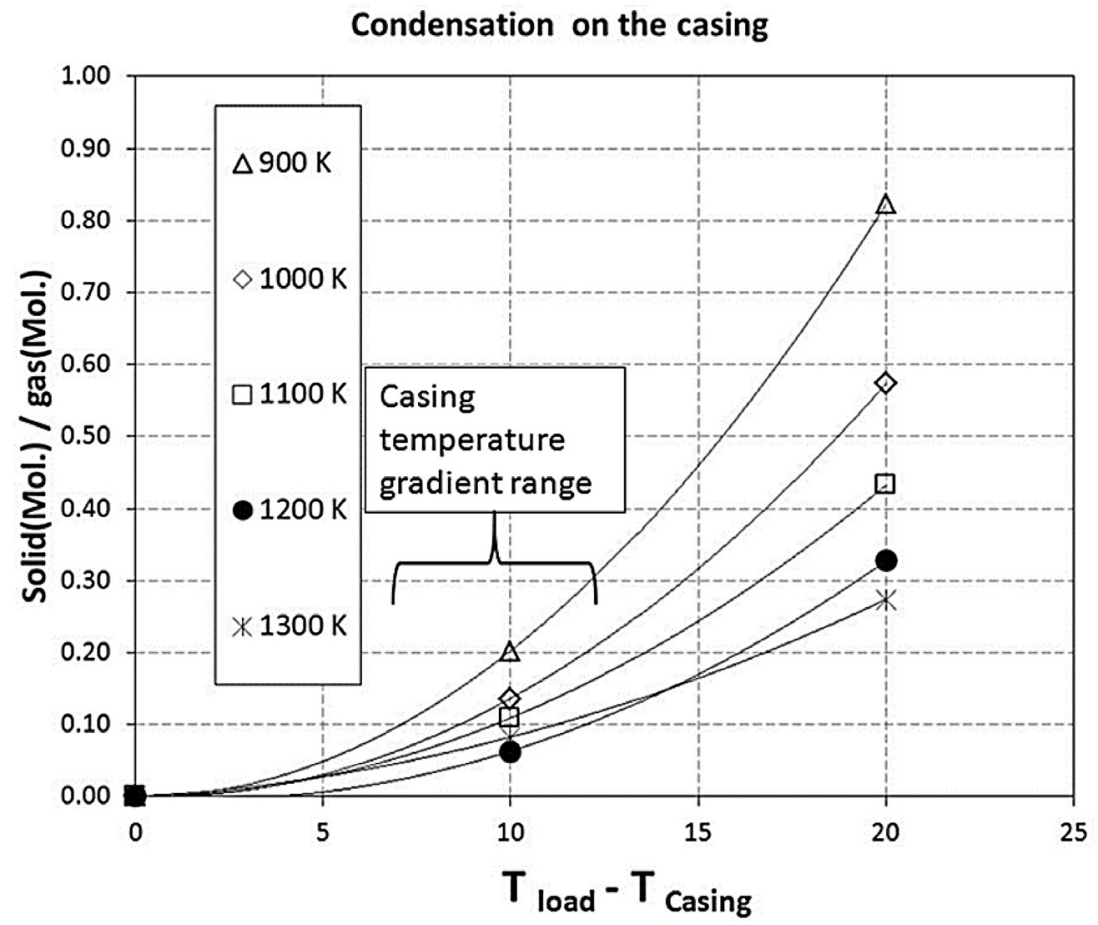

Fig. 9. Partition coefficient between the solid phase as condensed on the casing and the gaseous phase vaporizing from the load. 
flow coming from the vapour, taking into account of the cycle duration. Our calculations give 0.0672 moles of $\mathrm{Ag}_{0.97}-\mathrm{Cu}_{0.03}$ alloy (molar fractions) deposited per brazing cycle, corresponding to a layer of $0.69 \mu \mathrm{m}$ thickness.

As the deposited layers for each cycle are very thin (thickness $\approx 0.7 \mu$ ) and probably not high density with an appreciable specific surface, it will probably react with oxygen at least during the opening of the furnace for next loading or with other possible sources of oxygen during the cooling as for instance the oxygen content of the flushing $\mathrm{N}_{2}$ gas or the residual background of the vacuum pumping. To evaluate the oxygen affinity of these Ag-Cu deposits, thermodynamic equilibrium calculations with the deposit composition were performed with increasing oxygen content in order to observe the formation of the first solid oxide and to quantify the quantity of oxygen that can be dissolved in this deposited alloy layer. $\mathrm{Cu}_{2} \mathrm{O}$ solid is calculated as the first and only formed oxide from room temperature until $1360 \mathrm{~K}$ that appears when the oxygen solubility limit is reached for the Ag-Cu deposits. Then we focused the calculations on the behaviour of the Ag-Cu-O system (at the above deposit composition) - mainly the oxygen pressure and the oxygen solubility at the oxide formation - in order to evaluate the extent of oxygen dissolution in the alloy that can be a tank which during next cycles of brazing processes generates memory effects (at least oxygen desorption). Indeed, under temperature decrease at the end of a brazing cycle, the deposited alloy $\left(\mathrm{Ag}_{0.97}-\mathrm{Cu}_{0.03}\right)$ in one cycle can adsorb oxygen until dissolution as well as other oxygen containing gaseous species as for instance $\mathrm{CO}(\mathrm{g})$ or gaseous oxides, whereas during the next cycle under temperature rising the deposit can desorb its oxygen via different gaseous species. More, the thickness of the former deposited layers can be only increased at each brazing cycle although some vaporization also occurs and finally the oxygen storage capacity increases.

The deposited alloy composition is drawn in Figure 10 on the Ag-Cu binary phase diagram. The deposit is mainly pure $\mathrm{Cu}$ with a small quantity of $[\mathrm{Ag}, \mathrm{Cu}]$ solid so- lution between 400 and $1020 \mathrm{~K}$, then [Ag,Cu] solid solution in the range 1020-1120 K, and above it is a liquid. As calculated above, for all these ranges the oxygen effect - at saturation - is the only formation of $\mathrm{Cu}_{2} \mathrm{O}$ oxide. The calculated main gaseous species in the vapour phase of the $\left[\mathrm{Ag}, \mathrm{Cu}, \mathrm{O}-\mathrm{Cu}_{2} \mathrm{O}\right.$ ] system at the composition of the deposits is $\mathrm{O}_{2}(\mathrm{~g})$ and its partial pressure at the solubility limit is represented by the relations:

$$
\begin{aligned}
& \log p\left(\mathrm{O}_{2}\right) / \mathrm{Pa}= \\
& \quad-17776 / T+12.8682(400-1020 \mathrm{~K})
\end{aligned}
$$$$
\text { Triphasic } \mathrm{Cu}-\mathrm{Ag}(\mathrm{Cu}) \text { solution }
$$

$\log p\left(\mathrm{O}_{2}\right) / \mathrm{Pa}=$

$$
-23920 / T+20.716(1020-1120 \mathrm{~K})
$$$$
\text { for }(\mathrm{Ag}, \mathrm{Cu}) \text { solution (alloy) }
$$

$\log p\left(\mathrm{O}_{2}\right) / \mathrm{Pa}=$

$\log \mathrm{p}(\mathrm{O} 2)=-37624 / T+32.288(1120-1300 \mathrm{~K})$

for the liquid phase.

For the same system, the temperature dependence of the oxygen mole fraction $\left(X_{O}\right)$ at saturation in the solid and liquid solutions (maximum oxygen solubility) is described by the equations:

$\log X_{\mathrm{O}}=-10480 / \mathrm{T}+3.9889(400-1020 \mathrm{~K})$

$\log X_{\mathrm{O}}=-13296 / T+7.6565(1020-1120 \mathrm{~K})$

$\log X_{\mathrm{O}}=-18974 / T+12.56(1120-1300 \mathrm{~K})$.

\section{Results: Steady-state equilibria 71 with background oxygen}

\subsection{Influence of the flushed $\mathbf{N}_{2}$ cooling gas on formation of oxides deposits (layers)}

54 55 56 57 58 59 60 61 62 63

In order to decrease the room temperature recovering time of the load which may be very long under vacuum, a nitrogen flushing gas is used assisted by venting the gas in the furnace with a turbine. The oxygen quantity introduced in the furnace by the cooling gas, is calculated using ideal gas law and impurities data furnished by the supplier:

$$
\mathrm{N}_{\mathrm{O}_{2}}=\frac{\left[\mathrm{O}_{2}\right] p V}{R T}
$$




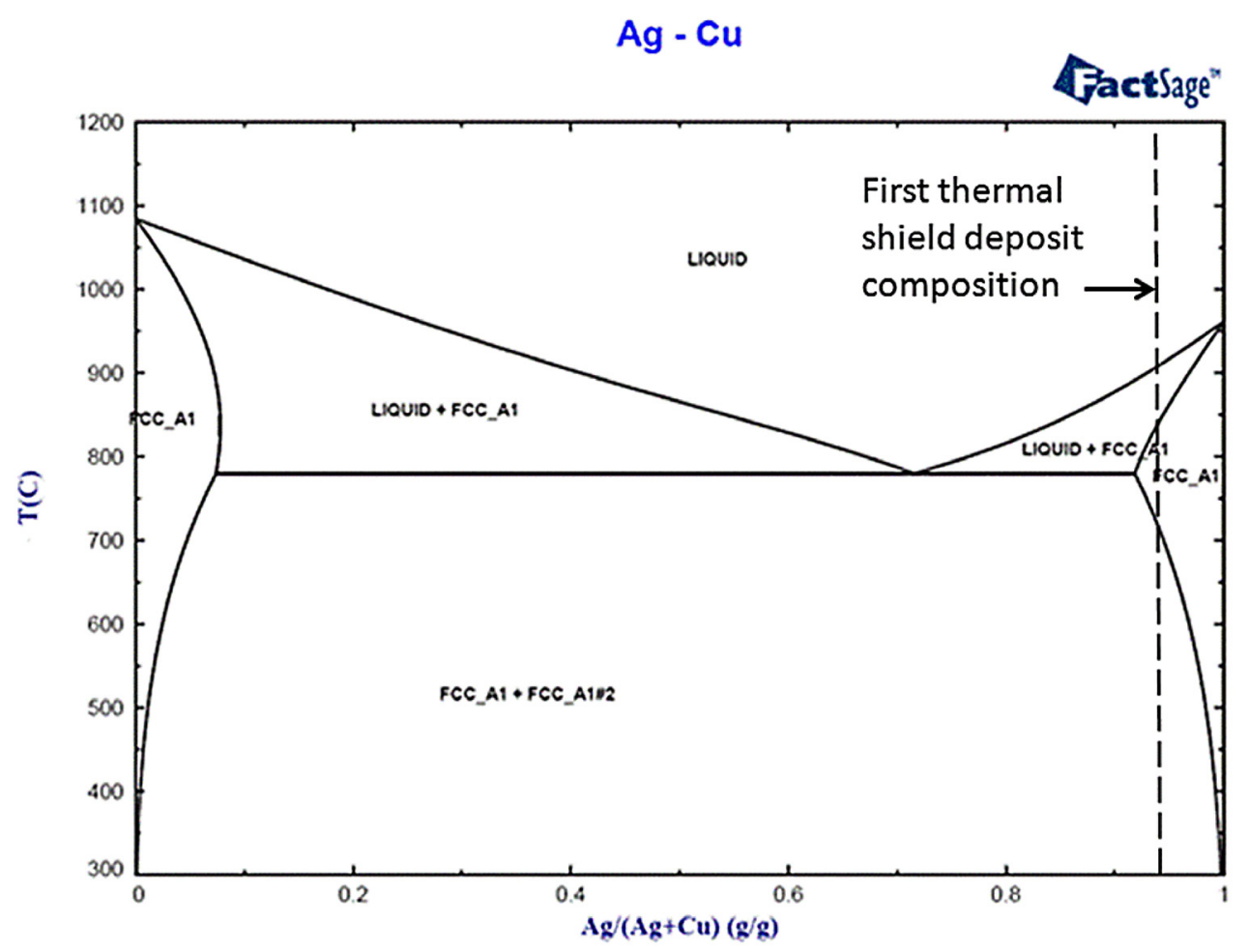

Fig. 10. Optimized $[\mathrm{Ag}-\mathrm{Cu}]$ binary phase diagram from thermodynamic and phase diagram data issued from literature.

1 where:

$\left[\mathrm{O}_{2}\right]$ - oxygen impurities content $(10 \mathrm{ppm}$ in volume) $/ \mathrm{m}^{3}$;

4 - final furnace pressure/Pa (101325 Pa);

$5 V$ - furnace volume $/ \mathrm{m}^{3}\left(2.4 \mathrm{~m}^{3}\right)$ or total vol-

6 ume of the introduced flushing gas;

$R$-ideal gas constant (J.mol $\left.{ }^{-1} \mathrm{~K}^{-1}\right)$;

$T$ - temperature $(\mathrm{K})$.

9 Note that the cooling gas is flushed to fill 10 up and then maintain the furnace at a pres11 sure slightly under 1 bar during the cooling 12 cycle and consequently the total cooling gas 13 volume amounts to the furnace volume.
A first step is to evaluate the possibility of oxides formation at the surface of the parts or any deposit when comparing different oxygen potentials. For this we compare the temperature dependence of the final oxygen impurity partial pressure imposed by the flushing gas (furnace filled at 1 bar) in Figure 11 with the one existing at saturation of the one brazing cycle formed deposit or of the different alloys of the loading. Remind that the formed oxide is first the $\mathrm{Cu}_{2} \mathrm{O}(\mathrm{s})$ except for the $[\mathrm{Cu}-\mathrm{Cr}]$ contacts where $\mathrm{Cr}_{2} \mathrm{O}_{3}(\mathrm{~s})$ may be formed and [Cu-Ag-Ni] braze where $\mathrm{NiO}(\mathrm{s})$ may be formed.

We observe that whatever would be the temperature at the input of the flushing gas, the nominal oxygen partial pressure in the flushing gas is sufficient to oxidize the deposits and the parts surfaces, and this feature is most probable when temperature decreases although the reaction kinetics becomes unfavourable.

A second step is to compare the oxygen quantities introduced in the furnace by the flushed gas volume during the cooling and that for saturation of the deposits, this last material being probably the most reactive due to its "native" nature. In Figure 12 we compare the oxygen quantity introduced when flushing the furnace (one full gas load) with the oxygen quantity for saturation of the one brazing cycle deposit. We observe that the recent and last deposited layer should be readily saturated below $1330 \mathrm{~K}$, and consequently there is enough oxygen to also react with the parts namely when temperature decreases. 
I Nuta et al.: Metall. Res. Technol.

\section{$\mathrm{O}_{2}$ partial pressures for oxide formation}

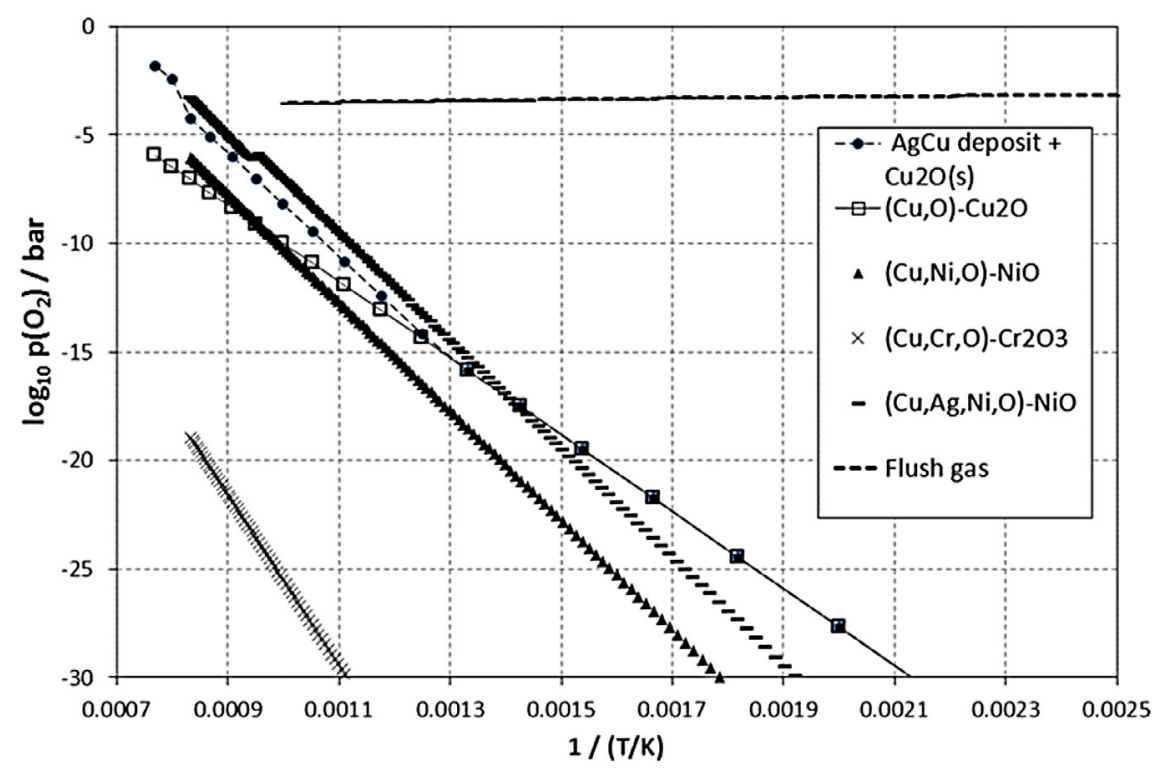

Fig. 11. Comparison of the decimal logarithm of $\mathrm{O}_{2}(\mathrm{~g})$ equilibrium partial pressures at the first oxides formation of the different materials of the load with the partial pressure of $\mathrm{O}_{2}(\mathrm{~g})$ in the flushing gas.

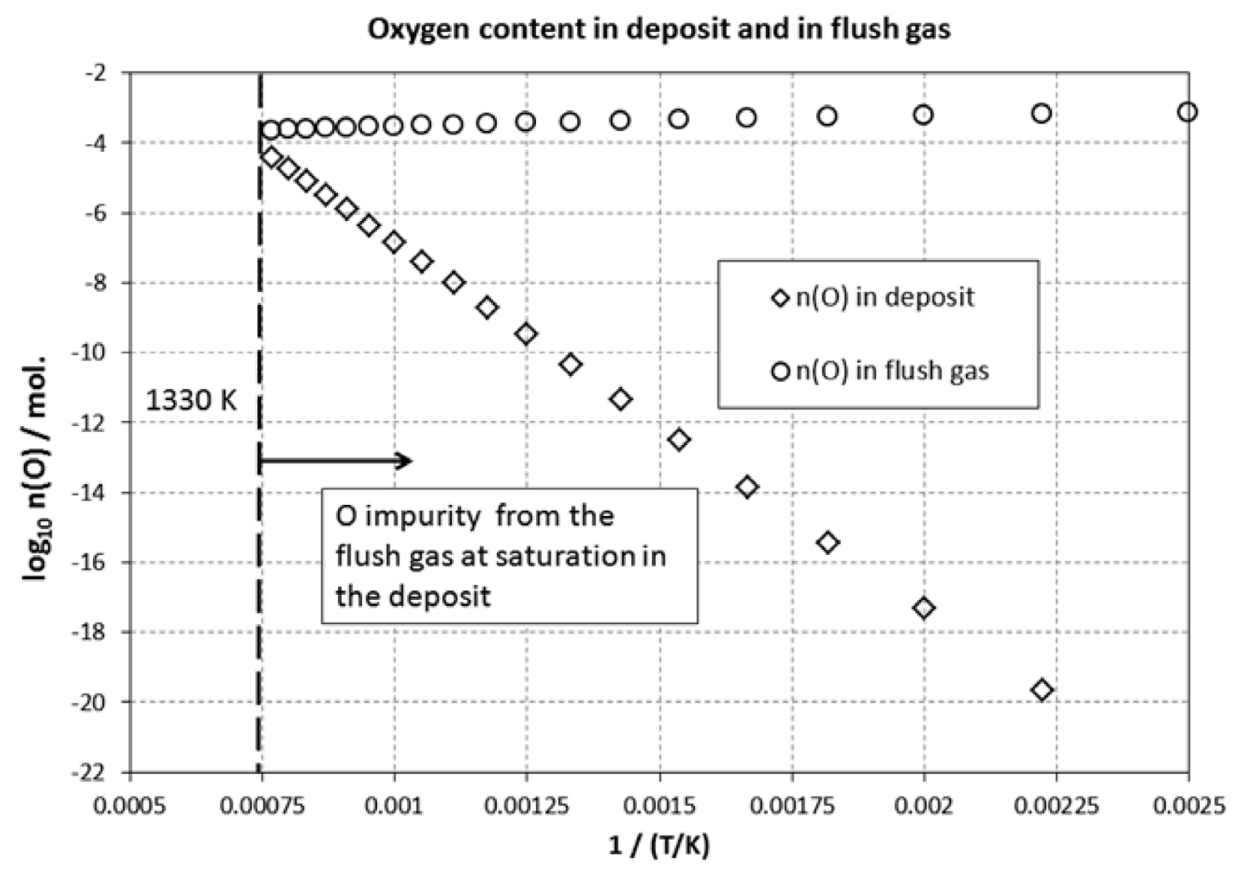

Fig. 12. Comparison of the decimal logarithm of the number of $\mathrm{O}$ moles at saturation in the one brazing cycle $[\mathrm{Ag}-\mathrm{Cu}]$ deposit on the casing and the number of $\mathrm{O}$ moles contained in the flushing gas. 
3 fect of oxygen will be its competitive dissolu4 tion in the different parts and in the deposit, 5 leading to non-saturation of the deposits 6 from only one brazing cycle. This situation 7 will change after a great number of cycles 8 since the successive deposited layers of [Ag$9 \mathrm{Cu}$ alloys should accumulate more oxygen 10 than other parts materials.

\subsection{Influence of residual pumping pressure on steady-state formation of surface oxides at resistor}

Under high vacuum, i.e. in the molecular regime, the oxygen partial pressure value in the furnace is not the pertinent parameter that determines the formation of an oxide at the surface of any metallic part when some volatile oxides are formed. Indeed, under vacuum, the metallic surfaces are not submitted directly to an oxygen partial pressure in the sense of an applied mechanical pressure but are submitted to impinging incident molecular flows from the background gas containing oxygen or molecules with oxygen $\left(\mathrm{O}_{2}, \mathrm{O}, \mathrm{CO}, \mathrm{H}_{2} \mathrm{O}\right.$, etc.) coming from the pumps at room temperature - pumps work as a dynamic join with a residual back flow corresponding to their pressure limits) - whereas the metal plus or minus saturated with oxygen can also evaporate oxygen and/or volatile oxides when temperature increases. Consequently the oxygen partial pressure at the surface of the parts is determined by the steady-state atomic flow balance of incident and evaporated oxygen atomic flows at the surface.

The total evaporated flow of oxygen $-\mathrm{F}_{\mathrm{O}}$ (tot.evap.) in number of $\mathrm{O}$ moles - is written taking into account the known gaseous molecules and for each VI part in Table 3. The incident oxygen flow on the parts and on the deposit at first thermal shield during the brazing treatment is coming from the background vacuum in the furnace (cold walls at temperature $T_{\text {housing }} \approx 300 \mathrm{~K}$ ) through the two casing orifices (total surface $S_{\text {orif }}$ ).

The oxygen pressure at walls in the furnace $p_{\mathrm{O}_{2}}^{\text {furnace }}$ is fixed as a steady-state pressure by the vacuum pumping capacities. Note that this pressure is not constant when the parts are degassing due to limiting values of the pumping capacity and a succession of steady-states is followed by the vacuum gauges, but finally after a while this pressure will reach the vacuum limits as fixed by the manufacturer. The vacuum limit in the present furnace is $\approx 2 \times 10^{-6} \mathrm{mbar}$ range. This range is depending on the degassing regime. As the pumping device and the furnace itself operates under reductive conditions due to predominantly metallic parts (a quadrupole filter can control this feature) we can consider that the oxygen species $\left(\mathrm{O}_{2}(\mathrm{~g})+\mathrm{O}(\mathrm{g})\right.$ $\left.+\mathrm{CO}(\mathrm{g})+\mathrm{H}_{2} \mathrm{O}(\mathrm{g})\right)$ are in the range $10 \%$ to $1 \%$ of the total measured pressures (mainly $\mathrm{N}_{2}+\mathrm{H}_{2}+$ hydrocarbons) in the ultimate background vacuum and consequently the equivalent oxygen partial pressure ranges from $\approx 2 \times 10^{-10}$ to $2 \times 10^{-11}$ bar.

This total incident atomic $\mathrm{O}$ flow on the parts is thus, flowing through the casing orifices,

$$
F_{\mathrm{O}}^{\text {inc }}=\frac{2 p_{\mathrm{O}_{2}}^{\text {furnace }} S_{\text {Orif }}}{\sqrt{2 \pi R T_{\text {Housing }} M_{\mathrm{O}_{2}}}}
$$

This incident flow into the casing will react with the different parts as the resistor or the load and thus form oxides - solid or gaseous. Before the formation of solid oxides, the only formation of gaseous oxides added to $\mathrm{O}(\mathrm{g})$ and $\mathrm{O}_{2}(\mathrm{~g})$ evaporating from the different metallic surfaces balances the incident oxygen flow and a steady-state is established between oxygen condensation/adsorption and total oxygen vaporization/desorption. The steady-state oxygen flow equilibrium for instance at the surface $S_{r}$ of the resistor at temperature $T$ is for instance,

$$
\begin{aligned}
& \frac{2 p_{\mathrm{O}_{2}}^{\text {furnace }} S_{\text {Orif }}}{\sqrt{2 \pi R T_{\text {Housing } M_{\mathrm{O}_{2}}}}}=\frac{2 p_{\mathrm{O}_{2}} S_{r}}{\sqrt{2 \pi R T M_{\mathrm{O}_{2}}}} \\
& +\frac{p_{O} S_{r}}{\sqrt{2 \pi R T M_{O}}}+\frac{p_{\mathrm{MoO}} S_{r}}{\sqrt{2 \pi R T M_{\mathrm{MoO}}}} \\
& +\frac{2 p_{\mathrm{MoO}_{2}} S_{r}}{\sqrt{2 \pi R T M_{\mathrm{MoO}_{2}}}}+\frac{3 p_{\mathrm{MoO}_{3}} S_{r}}{\sqrt{2 \pi R T M_{\mathrm{MoO}_{3}}}} \\
& +\frac{6 p_{\mathrm{Mo}_{2} \mathrm{O}_{6}} S_{r}}{\sqrt{2 \pi R T M_{\mathrm{Mo}_{2} \mathrm{O}_{6}}}}+\frac{8 p_{\mathrm{Mo}_{3} \mathrm{O}_{8}} S_{r}}{\sqrt{2 \pi R T M_{\mathrm{Mo}_{3} \mathrm{O}_{8}}}} \\
& +\frac{9 p_{\mathrm{Mo}_{3} \mathrm{O}_{9}} S_{r}}{\sqrt{2 \pi R T M_{\mathrm{Mo}_{3} \mathrm{O}_{9}}}}+\frac{12 p_{\mathrm{Mo}_{4} \mathrm{O}_{12} S_{r}}}{\sqrt{2 \pi R T M_{\mathrm{Mo}_{4} \mathrm{O}_{12}}}}
\end{aligned}
$$


Table 3. Relations to calculate the total atomic vaporization flows of oxygen $\mathrm{F}_{\mathrm{O}}$ as related to different gaseous species vaporizing in the brazing furnace.

\begin{tabular}{cl}
\hline $\begin{array}{c}\text { Deposit and Solder } \\
\text { Cu-Ag alloys }\end{array}$ & $\mathrm{F}_{\mathrm{O}}$ (tot. evap) $=2 \mathrm{~F}\left(\mathrm{O}_{2}\right)+\mathrm{F}(\mathrm{O})+3 \mathrm{~F}\left(\mathrm{O}_{3}\right)+\mathrm{F}(\mathrm{CuO})+\mathrm{F}(\mathrm{AgO})$ \\
\hline Bowls: Cu-Ni alloys & $\mathrm{F}_{\mathrm{O}}$ (tot. evap) $=2 \mathrm{~F}\left(\mathrm{O}_{2}\right)+\mathrm{F}(\mathrm{O})+3 \mathrm{~F}\left(\mathrm{O}_{3}\right)+\mathrm{F}(\mathrm{CuO})+\mathrm{F}(\mathrm{NiO})$ \\
\hline Contacts: Cu-Cr alloys & $\begin{array}{l}\mathrm{F}_{\mathrm{O}}\left(\text { tot. evap) }=2 \mathrm{~F}\left(\mathrm{O}_{2}\right)+\mathrm{F}(\mathrm{O})+3 \mathrm{~F}\left(\mathrm{O}_{3}\right)+\mathrm{F}(\mathrm{CuO})+\mathrm{F}(\mathrm{CrO})\right. \\
+2 \mathrm{~F}\left(\mathrm{CrO}_{2}\right)+\mathrm{F}\left(\mathrm{Cr}_{2} \mathrm{O}\right)+3 \mathrm{~F}\left(\mathrm{CrO}_{3}\right)+2 \mathrm{~F}\left(\mathrm{Cr}_{2} \mathrm{O}_{2}\right)+3 \mathrm{~F}\left(\mathrm{Cr}_{2} \mathrm{O}_{3}\right)\end{array}$ \\
\hline $\mathrm{Cu}(\mathrm{OFHC})$ parts & $\mathrm{F}_{\mathrm{O}}$ (tot. evap) $=2 \mathrm{~F}\left(\mathrm{O}_{2}\right)+\mathrm{F}(\mathrm{O})+3 \mathrm{~F}\left(\mathrm{O}_{3}\right)+\mathrm{F}(\mathrm{CuO})$ \\
\hline Mo resistor & $\mathrm{F}_{\mathrm{O}}\left(\right.$ tot. evap) $=2 \mathrm{~F}\left(\mathrm{O}_{2}\right)+\mathrm{F}(\mathrm{O})+3 \mathrm{~F}\left(\mathrm{O}_{3}\right)+\mathrm{F}(\mathrm{MoO})+2 \mathrm{~F}_{\left(\mathrm{MoO}_{2}\right)+3}$ \\
& $\left.\mathrm{F}\left(\mathrm{MoO}_{3}\right)+6 \mathrm{~F}\left(\mathrm{Mo}_{2} \mathrm{O}_{6}\right)+8 \mathrm{~F}\left(\mathrm{Mo}_{3} \mathrm{O}_{8}\right)+9 \mathrm{~F}\left(\mathrm{Mo}_{3} \mathrm{O}_{8}\right)+12 \mathrm{Fo}_{4} \mathrm{O}_{12}\right)$ \\
\hline
\end{tabular}

1 In this relation the oxygen pressure at the surface (right side of the present equation) is a steady-state surface oxygen pressure. Reversely, taking into account of the oxygen pressure at the formation of the first solid oxide of molybdenum $\mathrm{MoO}_{2}(\mathrm{~s})$, the critical oxygen partial pressure $p_{\mathrm{O}_{2}}$ (crit) at the pumping aperture or cold walls of the furnace able to start to oxidize the resistor into $\mathrm{MoO}_{2}$ (s) becomes,

$$
\begin{aligned}
& p_{\mathrm{O}_{2}}(\text { crit })=\frac{\sqrt{T_{\text {Housing }} M_{\mathrm{O}_{2}}}}{2 \sqrt{T_{r}}} \frac{S_{r}}{S_{\text {Orif }}} \\
& \times\left(\frac{2 p_{\mathrm{O}_{2}}}{\sqrt{\mathrm{M}_{\mathrm{O}_{2}}}}+\frac{p_{\mathrm{O}}}{\sqrt{M_{\mathrm{O}}}}+\frac{p_{\mathrm{MoO}}}{\sqrt{M_{\mathrm{MoO}}}}+\frac{2 p_{\mathrm{MoO}_{2}}}{\sqrt{M_{\mathrm{MoO}_{2}}}}\right. \\
& \left.+\frac{3 p_{\mathrm{MoO}_{3}}}{\sqrt{M_{\mathrm{MoO}_{3}}}}+\frac{6 p_{\mathrm{Mo}_{2} \mathrm{O}_{6}}}{\sqrt{M_{\mathrm{Mo}_{2} \mathrm{O}_{6}}}}+\ldots\right)
\end{aligned}
$$

diphasic $\mathrm{Mo}-\mathrm{MoO}_{2}$ (s) limit meaning that the resistor remains clean from surface oxide and at the same time the total Mo transported to the loaded parts decreases. In the same Figure 13 the pressures of background oxygen - either reduced at room temperature (without surfaces ratio) or with the resistor to casing orifice surfaces ratio - are presented and show the background pressure of the furnace becomes far above the diphasic $\mathrm{Mo}-\mathrm{MoO}_{2}$ limit to be able to oxidize the resistor material. Taking into account of the limiting oxygen pressure reached in the furnace $\left(10^{-10}\right.$ to $\left.10^{-11} \mathrm{bar}\right)$, the critical pressure in the casing becomes around $10^{-12}$ to $10^{-13}$ bar and we deduce that the critical temperature to oxidize the resistor is $\leq 1300 \mathrm{~K}$.

From the above calculation of the steadystate flows at the surface of the resistor, the evaporated Mo quantity is calculated - via its different gaseous species like Mo, $\mathrm{MoO}(\mathrm{g}), \mathrm{MoO}_{2}(\mathrm{~g})$, etc. - and then is converted into Mo layers able to condense on the parts. As the ratio between the respective surfaces (parts/resistor) is close to 1 , the Mo evaporation rate in micron per hour is a good estimate of probable condensed layers as presented in Figure 14. This figure shows that in our typical conditions the Mo built layers have a negligible thickness whatever is the resistor temperature.

However, in case of $\mathrm{O}_{2}(\mathrm{~g})$ over pressures i.e. $\approx 10^{-5}$ to $10^{-4}$ bar, and for higher temperatures of the resistor, i.e. $\approx 2000 \mathrm{~K}$, the condensation may build layers of $0.1 \mu \mathrm{m}$ for a cycle duration of 1 hour. So, during a brazing cycle, the oxygen pressure has to be monitored in order to avoid any appreciable Mo transport from the resistor in the casing. 


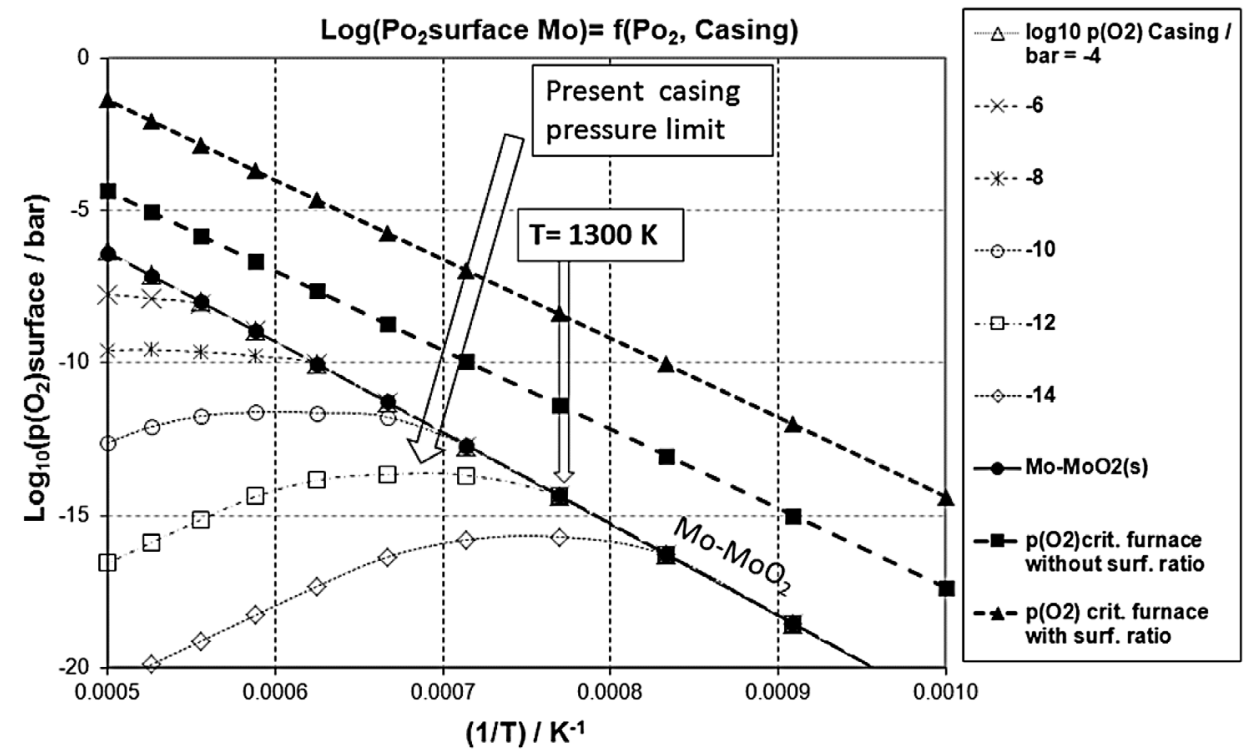

Fig. 13. Decimal logarithm of the steady-state $\mathrm{O}_{2}(\mathrm{~g})$ pressure at the surface of the Mo resistor as a function of the inverse of temperature of the resistor for different oxygen pressures in the background vacuum of the casing. The critical pressure corresponds to the formation of the first Mo(s) oxide at the surface of the Mo resistor: Mo-MoO2 line. Other lines correspond to the vacuum in the housing taking into account of the difference of temperatures or adding the conductance of the orifice between the casing and the housing.

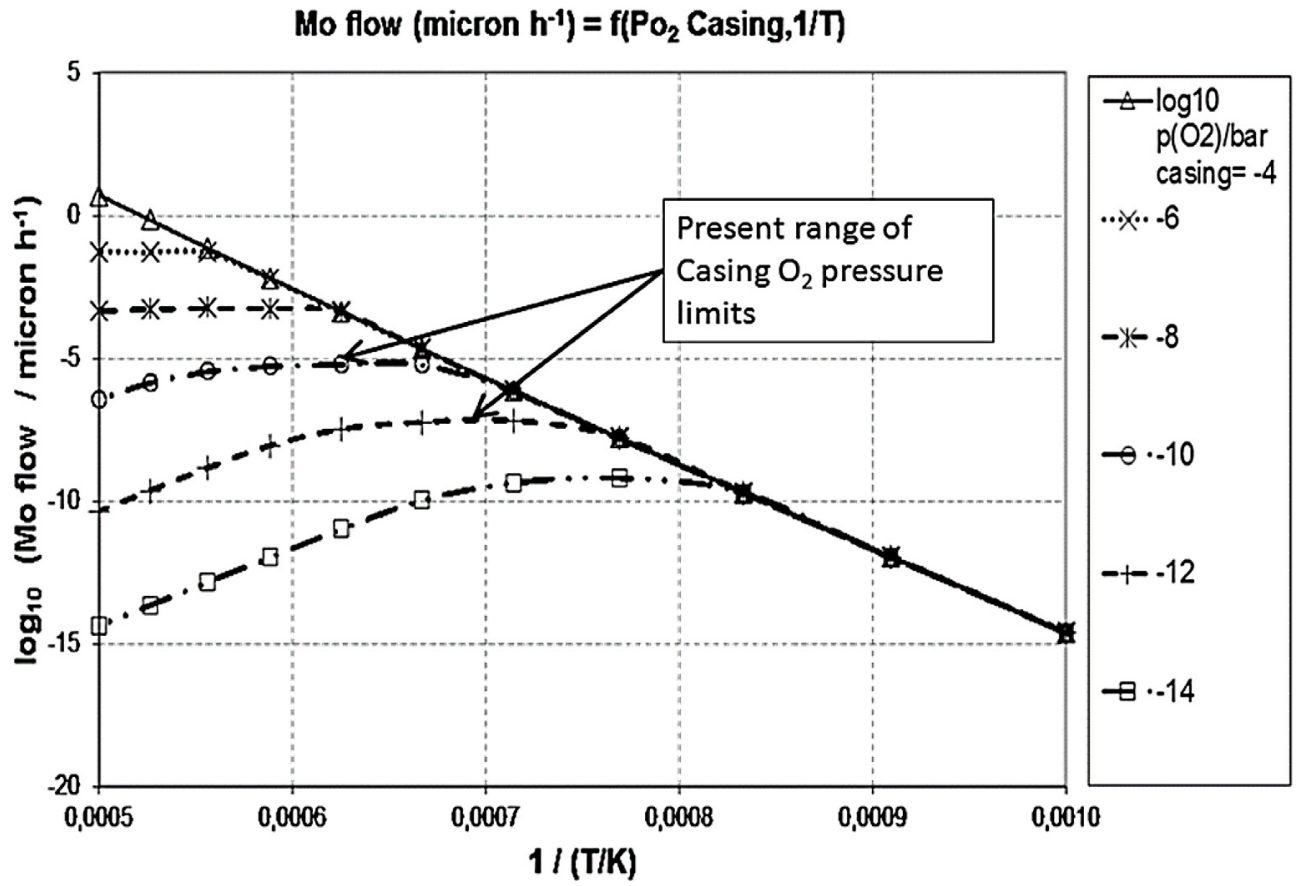

Fig. 14. Decimal logarithm of the vaporization (and equivalent) condensation flows - presented as layers - from the Mo resistor under background oxygen pressure in the casing. 


\subsection{Influence of residual pumping pressure on steady-state formation of surface oxides in the furnace}

As already calculated in the case of the resistor, for the $[\mathrm{Ag}, \mathrm{Cu}]$ deposits, the steady-state oxygen flow equilibrium for instance at the surface $S_{1}$ of the deposits on the first thermal shield at temperature $T$ of the casing and taking into account of the formation of gaseous oxides is for instance,

$$
\begin{aligned}
& \frac{2 p_{\mathrm{O}_{2}}^{\text {furnace }} S_{\text {Orif }}}{\sqrt{2 \pi R T_{\text {Housing }} M_{\mathrm{O}_{2}}}}=\frac{2 p_{\mathrm{O}_{2}} S_{1}}{\sqrt{2 \pi R T M_{\mathrm{O}_{2}}}} \\
& +\frac{p_{\mathrm{O}} S_{1}}{\sqrt{2 \pi R T M_{\mathrm{O}}}}+\frac{3 p_{\mathrm{O}_{3}} S_{1}}{\sqrt{2 \pi R T M_{\mathrm{O}_{3}}}} \\
& +\frac{p_{\mathrm{CuO}} S_{1}}{\sqrt{2 \pi R T M_{\mathrm{CuO}}}}+\frac{p_{\mathrm{AgO}} S_{1}}{\sqrt{2 \pi R T M_{\mathrm{AgO}}}}
\end{aligned}
$$

2 Reversely, taking into account of the oxygen pressure at the saturation limit of the deposited alloy the critical oxygen partial pressure $p_{\mathrm{O}_{2}}$ (crit) at the casing pumping aper6 ture or cold walls of the furnace able to 7 start to form $\mathrm{Cu}_{2} \mathrm{O}(\mathrm{s})$ at the deposit surface 18 becomes,

$$
\begin{gathered}
p_{\mathrm{O}_{2}} \text { (crit) }=\frac{\sqrt{T_{\text {Housing } M_{\mathrm{O}_{2}}}} \frac{S_{1}}{2 \sqrt{T}}\left(\frac{2 p_{\mathrm{O}_{2}}}{S_{\mathrm{Orif}}}\right.}{\sqrt{\mathrm{M}_{\mathrm{O}_{2}}}} \\
\left.+\frac{p_{\mathrm{O}}}{\sqrt{M_{\mathrm{O}}}}+\frac{3 p_{\mathrm{O}_{3}}}{\sqrt{M_{\mathrm{O}_{3}}}}+\frac{p_{\mathrm{CuO}}}{\sqrt{M_{\mathrm{CuO}}}}+\frac{p_{\mathrm{AgO}}}{\sqrt{M_{\mathrm{AgO}}}}\right) .
\end{gathered}
$$

In this relation the partial pressures in the right parenthesis are those corresponding to the [Cu-Ag-O alloys (O saturated) $\mathrm{Cu}_{2} \mathrm{O}(\mathrm{s})$ ] system equilibrium obtained directly from thermodynamic calculations performed for the deposited alloy composition

The same relation is written for each material of the loaded parts The different critical furnace oxygen pressures (at the furnace side of the pumping orifice of the casing) as a function of the inverse of temperature $\mathrm{T}$ of the load are presented in Figures 15 to 19. For furnace oxygen pressure values above the calculated critical ones the $\mathrm{Cu}_{2} \mathrm{O}(\mathrm{s})$ oxide will be formed on the deposit or pure $\mathrm{Cu}$ parts, $\mathrm{Cr}_{2} \mathrm{O}_{3}(\mathrm{~s})$ on $\mathrm{Cu}-\mathrm{Cr}$ contact tips and $\mathrm{NiO}(\mathrm{s})$ on the flanges or on the braze; whereas under this limit, oxygen remains dissolved in the deposit or parts materials as unsaturated solid solutions

As a conclusion for the critical oxygen pressure at pumping and related to different materials:

- $\mathrm{Cu}, \mathrm{Ag}$ and Ni components deliver very small $\mathrm{CuO}(\mathrm{g}), \mathrm{AgO}(\mathrm{g})$ or $\mathrm{NiO}(\mathrm{g})$ partial pressures whereas the main evaporated species is $\mathrm{O}_{2}(\mathrm{~g})$ meanwhile $\mathrm{O}(\mathrm{g})$ remains lower. Thus the evaporated and incident flows have practically the same composition (pure $\mathrm{O}_{2}(\mathrm{~g})$ ) and the equilibrium oxygen pressure above $(\mathrm{Cu}-\mathrm{Ag}$ $\mathrm{O})$ deposits, $\mathrm{Cu}-\mathrm{Ni}$ flanges or pure $\mathrm{Cu}$ OFHC parts and the incident oxygen pressures differ from their only emitted temperatures and surfaces according to the simple relation,

$$
\begin{aligned}
& \frac{p_{\mathrm{O}_{2}}^{\text {furnace }}}{p_{\mathrm{O}_{2}}^{\text {parts }}}=\frac{\sqrt{T_{\text {housing }}}}{\sqrt{T_{\text {parts. }}}} \frac{S_{\text {parts }}}{S_{\text {apertures }}} \\
& \approx \sqrt{\frac{300}{1200}} \frac{S_{\text {parts }}}{S_{\text {apertures }}} \approx \frac{1}{2} \frac{S_{\text {parts }}}{S_{\text {apertures }}}
\end{aligned}
$$

- Cr component has gaseous oxides that participate to the oxygen evaporation more than the oxygen pressure and consequently the critical oxygen furnace pressure becomes higher than the very low equilibrium $\mathrm{Cr}-\mathrm{Cr}_{2} \mathrm{O}_{3}$ pressure at the surface of the contacts.

In Figures 15 to 19 the critical temperatures above which de-oxidation occurs are quoted for the different materials taking into account of the oxygen pressure limit in the furnace. Considering these temperatures and the mean value of the brazing temperature $(\approx 116 \mathrm{~K})$ the only CuOFHC parts and deposits materials are not oxidized at the brazing temperature, the [CuNi] alloyed flanges slightly oxidize meanwhile the contact tips containing chromium and the brazes containing Ni will probably be sensitive to oxidation. For the contact tips in [Cu-Cr] alloys, the chromium oxides volatility remains not enough efficient to prevent the contact tips from oxidation except if higher temperatures are reached i.e. $>1430 \mathrm{~K}$.

These calculations take into account the behaviour of any part in front of the total oxygen flow entering the casing. Really, in the furnace we can consider that the oxygen 


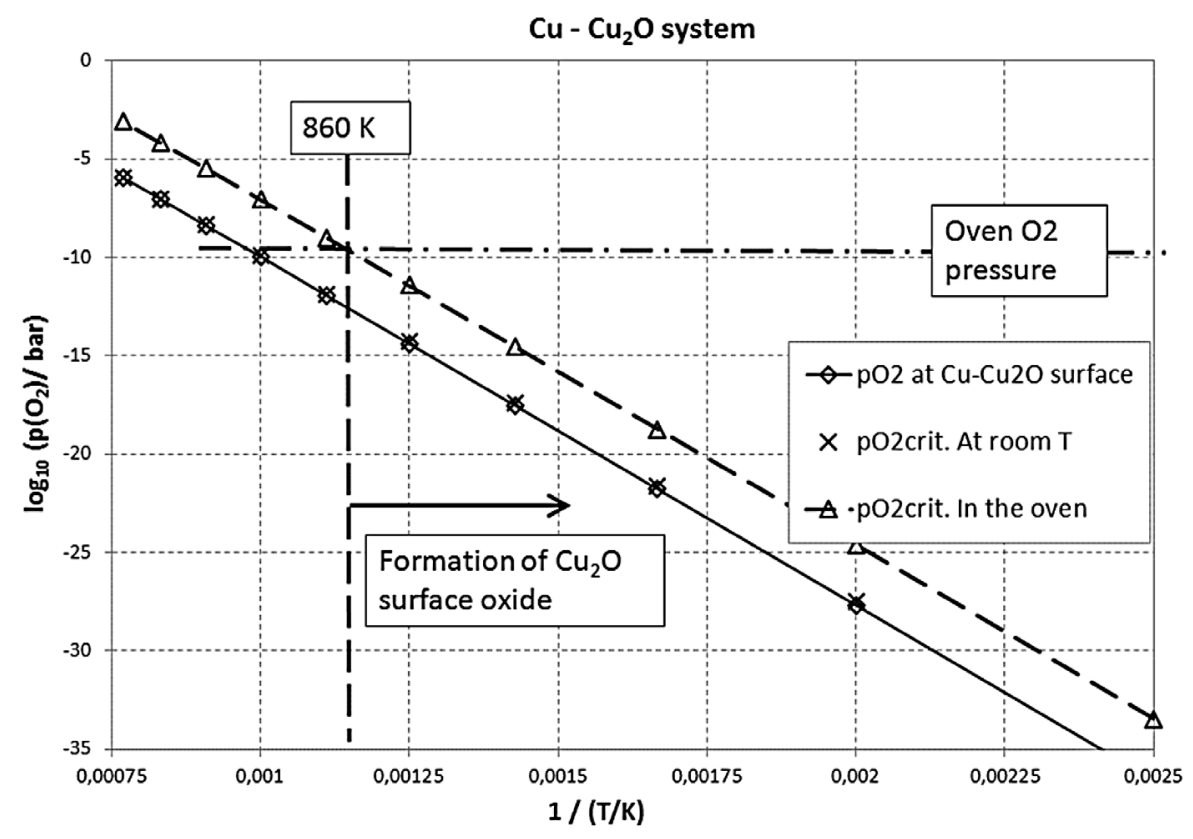

Fig. 15. Decimal logarithm of the partial pressures of $\mathrm{O}_{2}(\mathrm{~g})$ as a function of the inverse of temperature for the different $\mathrm{O}_{2}(\mathrm{~g})$ pressures existing at the formation of the first oxide $\mathrm{Cu}_{2} \mathrm{O}(\mathrm{s})$ : (i) at the surface of the OFHC parts in the casing, (ii) after temperature correction for vacuum background, (iii) and in the cold side of the furnace or pumps entrance.

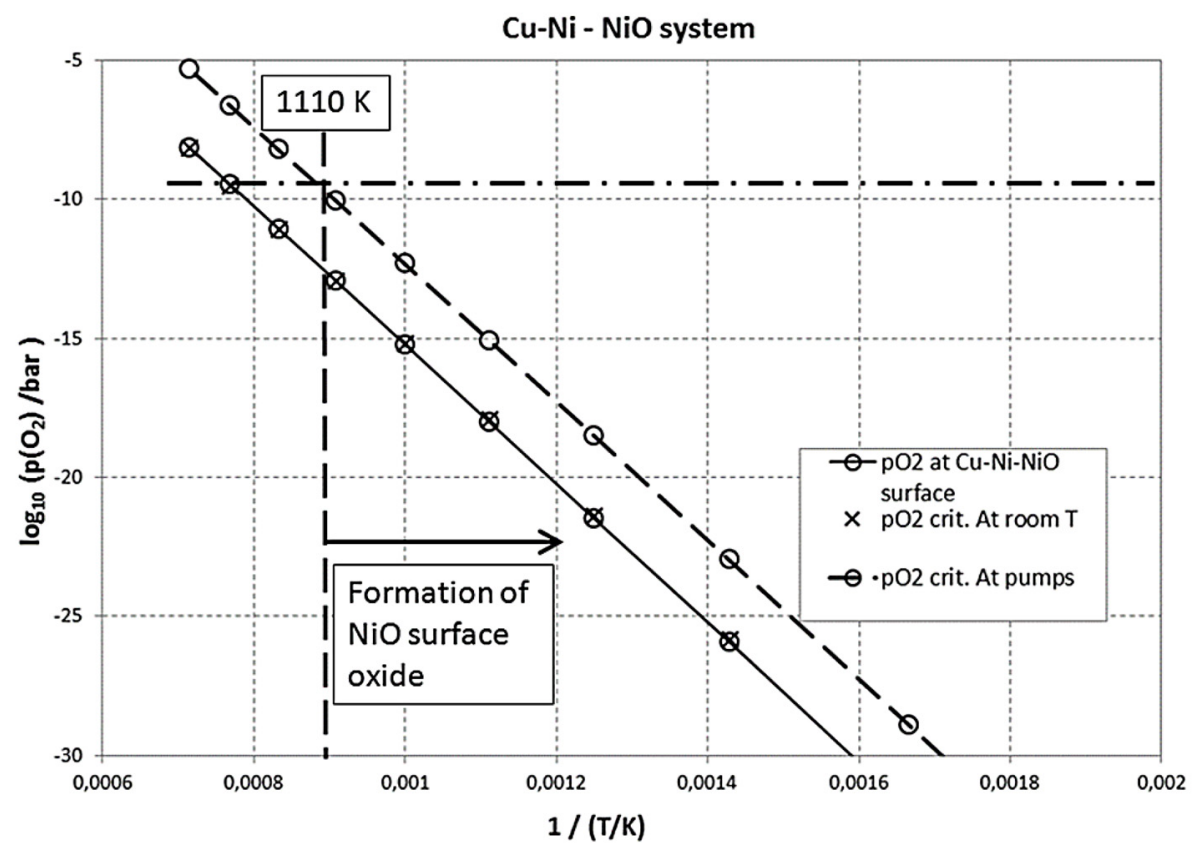

Fig. 16. Decimal logarithm of the partial pressures of $\mathrm{O}_{2}(\mathrm{~g})$ as a function of the inverse of temperature for the different $\mathrm{O}_{2}(\mathrm{~g})$ pressures existing at the formation of the first oxide $\mathrm{NiO}(\mathrm{s})$ : (i) at the surface of the [Cu-Ni] flanges in the casing, (ii) after temperature correction for vacuum background, (iii) and in the cold side of the furnace or pumps entrance. 
I Nuta et al.: Metall. Res. Technol.

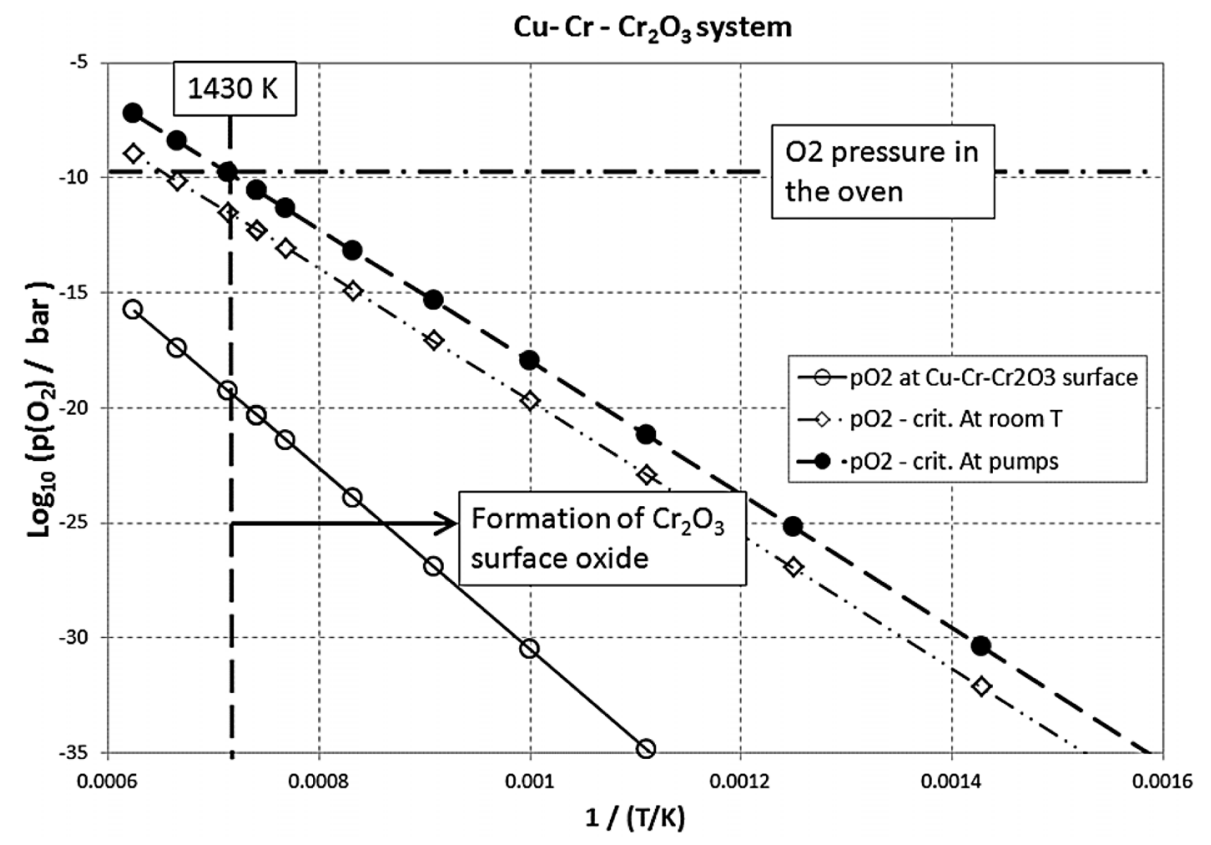

Fig. 17. Decimal logarithm of the partial pressures of $\mathrm{O}_{2}(\mathrm{~g})$ as a function of the inverse of temperature for the different $\mathrm{O}_{2}(\mathrm{~g})$ pressures existing at the formation of the first oxide $\mathrm{Cr}_{2} \mathrm{O}_{3}(\mathrm{~s})$ : (i) at the surface of the $[\mathrm{Cu}-\mathrm{Cr}]$ contact pads in the casing, (ii) after temperature correction for vacuum background, (iii) and in the cold side of the furnace or pumps entrance.

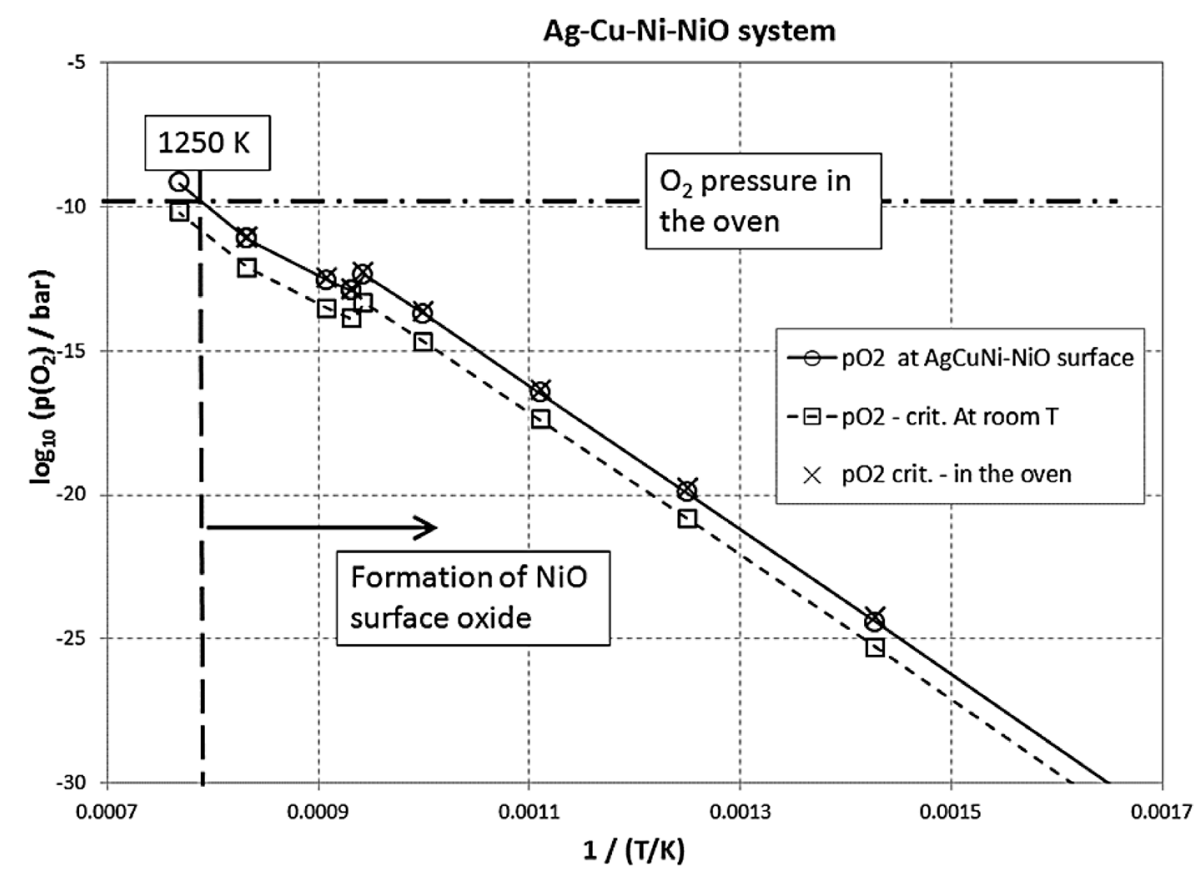

Fig. 18. Decimal logarithm of the partial pressures of $\mathrm{O}_{2}(\mathrm{~g})$ as a function of the inverse of temperature for the different $\mathrm{O}_{2}(\mathrm{~g})$ pressures existing at the formation of the first oxide $\mathrm{NiO}(\mathrm{s})$ : (i) at the surface of the [Ag-Cu-Ni] solder in the casing, (ii) after temperature correction for vacuum background, (iii) and in the cold side of the furnace or pumps entrance. 


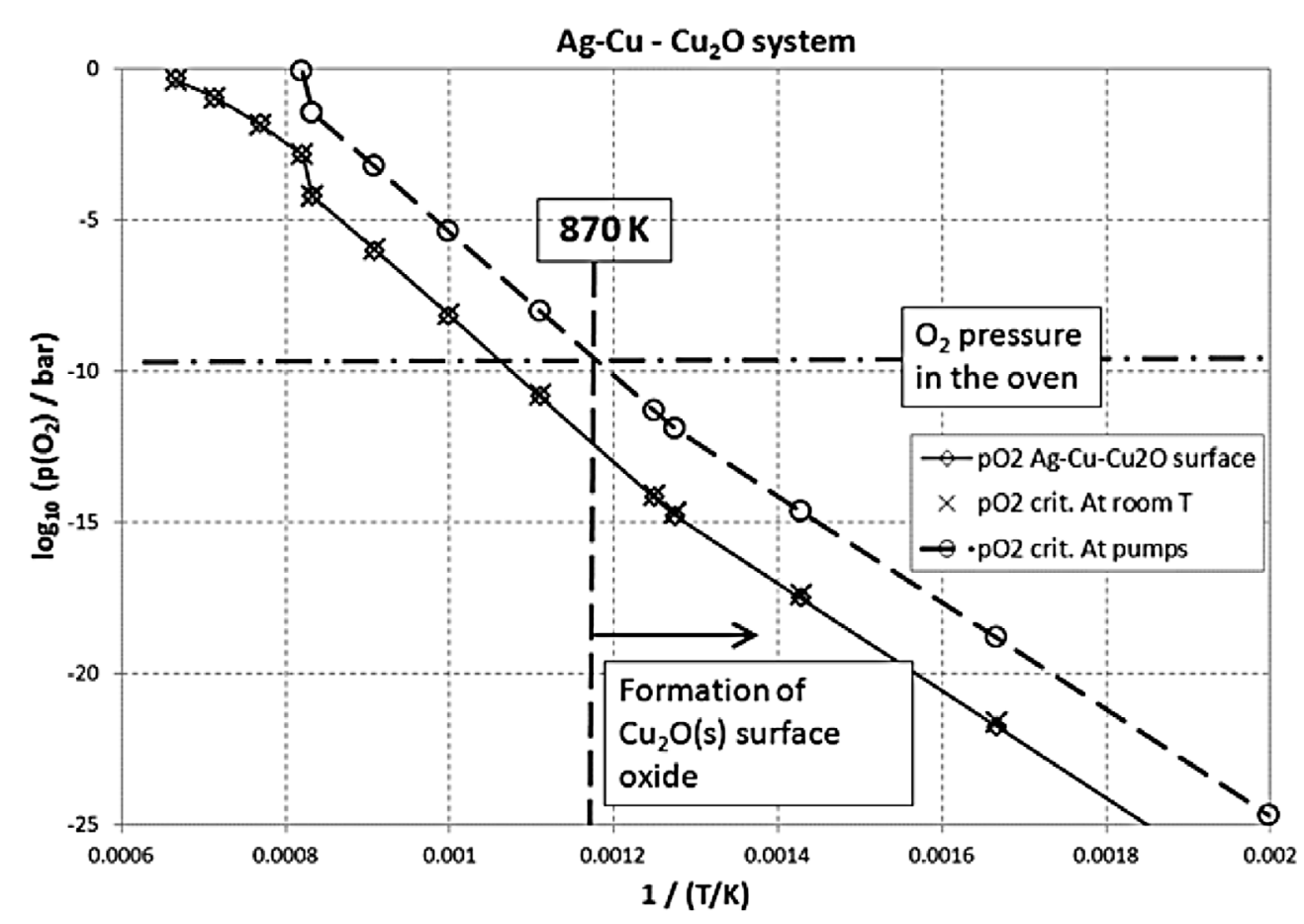

Fig. 19. Decimal logarithm of the partial pressures of $\mathrm{O}_{2}(\mathrm{~g})$ as a function of the inverse of temperature for the different $\mathrm{O}_{2}(\mathrm{~g})$ pressures existing at the formation of the first oxide $\mathrm{Cu}_{2} \mathrm{O}(\mathrm{s})$ : (i) at the surface of the $[\mathrm{Ag}-\mathrm{Cu}]$ deposits in the casing, (ii) after temperature correction for vacuum background, (iii) and in the cold side of the furnace or pump entrance.

1 flow entering by the casing orifices is dis2 tributed among all parts and consequently 3 the critical furnace oxygen pressure must 4 be balanced by the total flow evaporating 5 from all parts in the casing according to the 6 relation

$$
\begin{array}{r}
p_{\mathrm{O}_{2}}(\text { crit })=\left(\frac{S_{\text {total }}}{S_{\text {orif }}} \sqrt{\frac{T_{\text {housing }}}{T}} \frac{\sqrt{\mathrm{M}_{\mathrm{O}_{2}}}}{2}\right) \\
\times \sum_{i} \frac{S_{i}}{S_{\text {total }}}\left(\frac{2 p_{i, \mathrm{O}_{2}}}{\sqrt{M_{\mathrm{O}_{2}}}}+\frac{p_{i, \mathrm{O}}}{\sqrt{M_{\mathrm{O}}}}+\frac{3 p_{i, \mathrm{O}_{3}}}{\sqrt{M_{\mathrm{O}_{3}}}}\right. \\
\left.+\sum_{i} v_{i, j} \frac{p_{M_{i} \mathrm{O}_{\mathrm{j}}}}{\sqrt{M_{M_{i} \mathrm{O}_{j}}}}\right)
\end{array}
$$

7 Index $i$ is for each material surface, and in8 dex $j$ for the different evaporated molecules 9 from the $j$ material. Figure 20 presents the $10 \mathrm{O}_{2}(\mathrm{~g})$ critical furnace pressure calculated for 1 the whole load in the furnace as a function of 12 temperature. The critical temperature corresponding to the pressure limit in the furnace 14 decreases down to $830 \mathrm{~K}$ when taking into 5 account the full distribution on all surfaces 16 of the oxygen entrance flow in the casing.
As soon as temperature is decreased below this value, oxides can be formed on the deposits or at the surfaces of the brazed parts. At that time the formation and the growth rate of this oxide will depend on the balance between the total incident oxygen flow coming from the casing apertures minus the oxygen released by vaporization during the cooling and the oxygen diffusion into the bulk materials in view of their oxygen saturation.

\section{Conclusion and perspectives}

The brazing at temperatures higher than $1168 \mathrm{~K}$ - the eutectic temperature in the [Ag$\mathrm{Cu}-\mathrm{Ni}$ ] braze system - induces larger erosion of the parts by vaporization especially for the braze and consequently a rich silver deposit is formed on the first thermal shield of the casing. Thus, better homogeneous temperature for the load could allow a close approach of the needed eutectic temperature for the brazing process that will reduce these deposits. Indeed, the partial 
I Nuta et al.: Metall. Res. Technol.

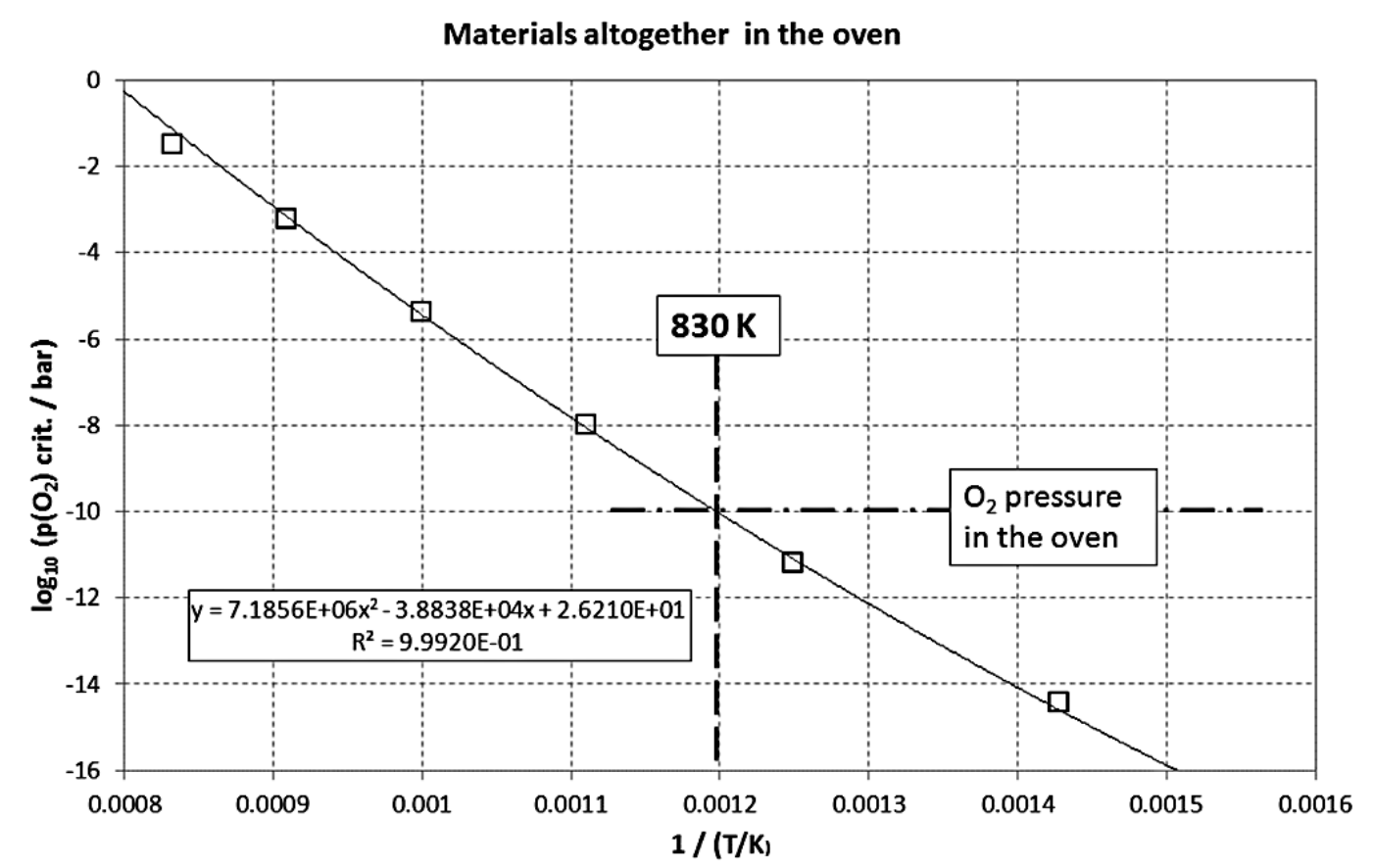

Fig. 20. Decimal logarithm of the critical partial pressure of $\mathrm{O}_{2}(\mathrm{~g})$ taking into account of the whole assembly of the load reported to the furnace background vacuum as a function of the inverse of temperature compared to the limiting $\mathrm{O}_{2}(\mathrm{~g})$ in the furnace cold walls or at pump entrance.

1 vapour pressures of metals in the furnace during the brazing process increase by a factor $\approx 10$ every $50 \mathrm{~K}$. Same observation works also for $\mathrm{Cu}$ vaporization that is sometimes deposited on ceramic parts.

The very small thickness of the deposits on the casing as well as their plus or minus fresh surface for each temperature brazing cycle allows asserting that the exposure of the deposited alloy to the residual oxygen in the furnace - coming from the flushing gas and from the pumping system - is going to pull its dissolution in a quasi-immediate time sequence (no limitation by diffusion) compared to room temperature recovering time and the oxygen content will be the one at equilibrium with furnace atmosphere as soon as deposited. The above calculations show that these deposits are at least almost saturated when a new cycle starts. More, during the cooling step, the oxygen impurity content of the flushing $\mathrm{N}_{2}$ gas (less than $10 \mathrm{ppm}$ ) introduced at about $1000 \mathrm{~K}$ is able to totally saturate the deposits and the remaining oxygen content can also oxidize the surfaces of the parts just brazed. An online pu- rification system for this gas could decrease at least by a factor 10 to 100 the oxidation processes occurring in the furnace. This is valuable also for copper parts since the solubility of oxygen in this material is important as well as in the braze material.

At the surface of the resistor, of the parts and of the deposit (inner surface of the casing) the steady-state reaction with the incident flow of oxygen coming from the vacuum pumps by reverse effusion at pressure limit into the casing through the casing orifices (front and rear) can form different oxides on these surfaces. At the higher temperatures - namely during the brazing - when good secondary vacuum conditions are established $\left(\approx 10^{-6}\right.$ mbar) these oxides are not formed and good conditions are established for the brazing process. It is important to note that some materials - for instance the Mo resistor and the Cu-Cr alloys - vaporize oxide molecules that delay the formation of oxides at their surface. For Mo - besides the vaporization of Mo that can occur if the resistor is overheated - the presence of oxygen may increase drastically the transport 
of Mo via its gaseous volatile oxides and this process may explain the Mo detection by EDX analysis in the deposits on the ceramic parts during some standard brazing runs.

Note that when some "boiling like phenomenon or material projections" are visually observed on the braze surface, these features are in fact a sign of high oxygen partial pressure that changes drastically the surface tension, generates surface tension gradients and creates some vortex in the liquid braze (Marangoni effect).

After brazing, as soon as the temperature decreases inside the furnace the external oxygen pressure - that also decreases as measured with vacuum gauges - cannot be low enough to prevent oxide formation below $830 \mathrm{~K}$ as calculated. The quantity of oxide formed at that time is related to temperature to the residual pumping pressure, to the casing orifice sections and to the diffusion of oxygen in the bulk of the parts. Probably the kinetics of oxidation will slow down also the dissolution process with temperature decrease. In order to avoid excessive oxide formation at surfaces of the parts it is preferable to decrease the back flow from the housings and pumps by these four steps: (i) use purified nitrogen for flushing the furnace; (ii) decreasing the temperature threshold level for nitrogen flushing; (iii) decreasing the nominal pressure limit related to the pumping capacities, and, finally; (iv) decreasing the casing apertures size when cooling.

Further some special "degassing" procedures must be planned to eliminate periodically the accumulated deposits along brazing cycles that are a source of oxygen storage. Oxygen gauges could help understanding the "role" of oxygen as a function of time along successive brazing cycles.

\section{References}

[1] L.T. Falkingham, The strengths and weaknesses of Vacuum Circuit Breaker technology, in Electric Power Equipment - Switching Technology (ICEPE-ST), 1st International Conference on, 2011

[2] D. Konig, The role of vacuum in circuit breaker technology, in Discharges and Electrical Insulation in Vacuum (ISDEIV), 25th International Symposium on, 2012

[3] S. Théoleyre, Techniques de coupure en moyenne tension, Techniques de l'ingénieur Réseaux électriques de distribution publique, 1999. base documentaire : TIB264DUO(ref. article : d4705).

[4] K.D. Carlson, The Knudsen Effusion Method, in The Characterization of High-Temperature Vapors, edited by J.L. Margrave, John Wiley \& Sons, Inc., New york, 1997, pp. 115-129

[5] E.D. Cater, The effusion method at age 69: current state of the art, in Characterization of High Temperature Vapors and Gases. 1979, J. Hastie, NBS MD: National Institute of Standards and Technology Sp. pub. 561/1, Gaithersburg. pp. 3-38

[6] G.M. Pound, J. Phys. Chem. Ref. Data 1 (1972) 135-146

[7] Scientific Group Thermodata Europe, Available from: http://www.sgte.org/.

[8] C. Bale, , et al., Calphad 26 (2002) 189-228

[9] B. Hallstedt, L.J. Gauckler, Calphad 27 (2003) 177-191

[10] B. Hallstedt, D. Risold, L. Gauckler, J. Phase Equilibria 15 (1994) 483-499

[11] I. Karakaya, W.T. Thompson, J. Phase Equilibria 13 (1992) 137-142

[12] H. Okamoto, J. Phase Equilibria 18 (1997) 402402

[13] M. Kowalski, P.J. Spencer, Calphad 19 (1995) 229-243

[14] H.-T. Luo, S.-W. Chen, J. Mater. Sci. 31 (1996) 5059-5067

[15] J. Assal, B. Hallstedt, L.J. Gauckler, J. Phase Equilibria 19 (1998) 351-360 